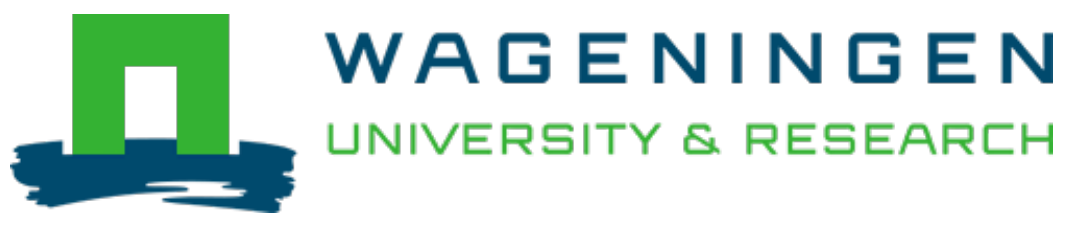

\title{
Understanding Differences in Climate Sensitivity Simulations of APSIM and DSSAT Crop Models
}

\author{
Handbook of Climate Change and Agroecosystems \\ Boote, K.J.; Adam, M.; Ahmad, I.; Ahmad, S.; Cammarano, Davide et al \\ https://doi.org/10.1142/9781786348791 0002
}

This publication is made publicly available in the institutional repository of Wageningen University and Research, under the terms of article $25 \mathrm{fa}$ of the Dutch Copyright Act, also known as the Amendment Taverne. This has been done with explicit consent by the author.

Article 25 fa states that the author of a short scientific work funded either wholly or partially by Dutch public funds is entitled to make that work publicly available for no consideration following a reasonable period of time after the work was first published, provided that clear reference is made to the source of the first publication of the work.

This publication is distributed under The Association of Universities in the Netherlands (VSNU) 'Article $25 \mathrm{fa}$ implementation' project. In this project research outputs of researchers employed by Dutch Universities that comply with the legal requirements of Article $25 \mathrm{fa}$ of the Dutch Copyright Act are distributed online and free of cost or other barriers in institutional repositories. Research outputs are distributed six months after their first online publication in the original published version and with proper attribution to the source of the original publication.

You are permitted to download and use the publication for personal purposes. All rights remain with the author(s) and / or copyright owner(s) of this work. Any use of the publication or parts of it other than authorised under article $25 \mathrm{fa}$ of the Dutch Copyright act is prohibited. Wageningen University \& Research and the author(s) of this publication shall not be held responsible or liable for any damages resulting from your (re)use of this publication.

For questions regarding the public availability of this publication please contact openscience.library@wur.nl 


\section{Chapter 2}

\section{Understanding Differences in Climate Sensitivity Simulations of APSIM and DSSAT Crop Models}

Kenneth J. Boote*, Myriam Adam ${ }^{\dagger}$,\|l\|, Ishfaq Ahmad ${ }^{\ddagger}$, Shakeel Ahmad ${ }^{\S}$, Davide Cammarano" ${ }^{\text {II }}$ Ashfaq Ahmad Chatthall, Lieven Claessens**, ${ }^{* \dagger}$, John Dimes ${ }^{\dagger}$, Wiltrud Durand ${ }^{\S \S}$, Bright S. Freduah ${ }^{\text {III }}$, Sridhar Gummadilll, John Hargreaves***, Gerrit Hoogenboom*, Sabine Homann-Kee Tui ${ }^{\dagger \dagger}$, James W. Jones*, Tasneem Khaliq", Dilys S. MacCarthy IIII, Patricia Masikati ${ }^{\dagger+t}$, Sonali McDermid ${ }^{\S \S}$, Kadiyala Dakshina Murthy ${ }^{\text {IIIIII }}$, Andree Nenkam ${ }^{\|\| \|}$, Cheryl Porter*,

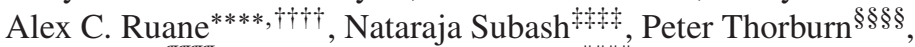
Pierre S. Traore ${ }^{\text {IIIIIII }}$, Geethalakshmi Vellingiri \|\|\|\|$\|$, and Syed Aftab Wajid"

* University of Florida, Gainesville, FL, USA

${ }^{\dagger}$ CIRAD, UMR AGAP, Bobo-Dioulasso, Burkina Faso

¥Climate Resilient Department, Asian Disaster Preparedness Center, Islamabad, Pakistan

$\S_{\text {Bahauddin Zakariya University, Multan, Pakistan }}$

II Purdue University, West Lafayette, Indiana

"Agro-Climatology Lab, Department of Agronomy, University of Agriculture, Faisalabad, Pakistan

** International Institute of Tropical Agriculture (IITA), Arusha, Tanzania

${ }^{\dagger \dagger}$ Wageningen University \& Research, Wageningen, the Netherlands

\$Self-employed, Toowoomba, Australia

$\S \S$ Bureau for Food and Agricultural Policy, Pretoria, South Africa

III Soil and Irrigation Research Centre, University of Ghana, Accra, Ghana

"I\| International Rice Research Institute, Los Baños, Philippines

*** Commonwealth Scientific and Industrial Research Organization, Toowoomba, Australia ${ }^{\dagger \dagger}$ International Crops Research Institute for the Semi-Arid Tropics (ICRISAT),

Bulawayo, Zimbabwe

+ World Agroforestry Centre, Lusaka, Zambia

$\S \S$ New York University, New York, NY, USA

IIIIII International Crops Research Institute for the Semi-arid Tropics (ICRISAT), Hyderabad, India

"| || International Crops Research Institute for the Semi-arid Tropics (ICRISAT), Bamako, Mali

****NASA GISS, New York, NY, USA 


\section{$\dagger+\dagger$ Center for Climate Systems Research, Columbia University, New York, NY, USA \\ +\$+ICAR-Indian Institute of Farming Systems Research, Uttar Pradesh, India \\ $\S \S \S$ Commonwealth Scientific and Industrial Research Organization, \\ Brisbane, Australia \\ IIIIIIII International Crops Research Institute for the Semi-arid Tropics (ICRISAT), \\ Dakar, Senegal \\ || || || Tamil Nadu Agricultural University, Coimbatore, India}

\section{Introduction}

In the Agricultural Model Intercomparison and Improvement Project (AgMIP) (Rosenzweig et al., 2013, 2017), we have explored and learned the value of using multiple crop models to project the effects of climate change on crop production, in order to provide model users with more confidence in the ensemble predictions of multiple models, as opposed to trusting the predictions of any single model. Simply stated, crop models have been developed by different modeling teams and are different in structure and parameterization. This causes the models to have somewhat different growth, development, and yield responses to given weather, management, and soil conditions.

In the AgMIP Regional Integrated Assessment (RIA) project, resources have limited us to using only two crop model systems: the Agricultural Production Systems Simulator (APSIM) and the Decision Support System for Agrotechnology Transfer (DSSAT). Our goal in this chapter is to identify and understand the differences between the APSIM and DSSAT models for maize, wheat, rice, sorghum, millet, and peanut for their responses to $\mathrm{CO}_{2}$, temperature, water, and $\mathrm{N}$ fertilization (CTWN). Comparison of crop system responses to these fundamental factors has proven productive for applications across a number of scales and AgMIP activities (Ruane et al., 2017).

Our approach will be to discuss model sensitivity to $\mathrm{N}$ fertilization, $\mathrm{CO}_{2}$ response, and rainfall separately and, in that order, considered over all the crops because the issues for response to $\mathrm{N}$ fertilizer and rainfall occur and repeat across the crop types, and are often similar for both the APSIM and DSSAT models. The $\mathrm{CO}_{2}$ response is unique as the contrast is mostly $\mathrm{C}-3$ versus $\mathrm{C}-4$ type crops, but the crops/models are similar within $\mathrm{C}-3$ or $\mathrm{C}-4$ crop types. For temperature responses, we follow one crop at a time, discussing model differences in simulated responses at different sites, including a discussion of parameterization that creates model differences for APSIM versus DSSAT. Based on the CTWN exercises, we illustrate how simulated responses to $\mathrm{CO}_{2}$ and rainfall are influenced by, and have interaction effects dependent on, $\mathrm{N}$ fertilization and the $\mathrm{N}$-supplying capacity of the soil. The responses to temperature and rainfall are dependent on the ambient conditions of sites for temperature and rainfall. 


\section{Materials and Methods}

\section{Introduction to APSIM crop models}

APSIM Version 7.7 (www.apsim.info) and its evolution as a farming systems research model for application in high- and low-production cropping systems around the world are described by McCown et al. (1996), Keating et al. (2003), and Holzworth et al. (2014). The APSIM software platform links modules of different crops (selected on a plug-in/plug-out basis, including crop mixtures) with common modules of soil water balance, surface organic matter, soil $\mathrm{N}$ and $\mathrm{C}$ balances (P optional), crop and soil management, and weather input and output/reporting. APSIM includes crop modules for many crops, including maize, sorghum, millet, wheat, peanut, and rice as simulated in this project. The crop modules (both C-3 and C-4) share a common template for crop development and biomass accumulation and partitioning, although APSIM-Maize (derived from CERES-Maize with modifications for tropical conditions (Carberry et al., 1989)) and APSIM-Wheat have yet to be standardized (but conform to the template in terms of their growth and development processes). The rice model in APSIM directly incorporates the ORYZA2000 model (Bouman and van Laar, 2006; Gaydon et al., 2012) and is also not standardized.

All APSIM crop models except APSIM-ORYZA use the radiation-use efficiency (RUE) approach, based on the fraction of light intercepted, species-specific RUE, and modifiers of RUE (depending on temperature, vapor pressure deficit (VPD), and $\mathrm{CO}_{2}$ when $>350 \mathrm{ppm}$ ). Daily biomass accumulation is the minimum of potential biomass derived for non-stressed intercepted radiation on a day and an estimate based on available soil water for transpiration on that day. The APSIM water balance is a tipping bucket method derived from CERES-Maize (Probert et al., 1998) and includes a dynamic Curve Number for estimating runoff using routines from the PERFECT model (Littleboy et al., 1999). The bare-soil curve number is adjusted for antecedent soil moisture conditions (typically to 450-mm depth) and variations in canopy and mulch cover effects over the course of a growing season.

Soil evaporation in APSIM uses the Priestley and Taylor (1972) approach to estimate potential atmospheric demand, adjusted for cover conditions of canopy and surface residues, and the Ritchie (1985) two-stage soil evaporation model to determine actual Es.

Transpiration is based on the transpiration efficiency (TE) approach. The TE method computes daily transpiration based on daily dry matter gain (from RUE module) multiplied by TE. The TE is a species-dependent function of VPD and $\mathrm{CO}_{2}$ that operates on daily VPD to estimate crop water demand.

The capabilities of APSIM to simulate $\mathrm{CO}_{2}$ effects on C-3 crop growth have been tested empirically with APSIM-Wheat and applied for all C-3 crops in APSIM as reported by Van Uytrecht and Thorburn (2017). Effects of the increasing levels 
of $\mathrm{CO}_{2}$ are captured by modifiers to RUE, TE, and a reduction in $\mathrm{N}$ stress on photosynthesis using look-up functions. The same modifier coefficients and $\mathrm{CO}_{2}$ effects as used for wheat are employed for all the APSIM C-3 crop modules in this project, except for APSIM-Maize and APSIM-Sorghum, for which $\mathrm{CO}_{2}$ does not modify RUE. APSIM-ORYZA uses leaf-level photosynthesis, which is sensitive to $\mathrm{CO}_{2}$ at the leaf level (Bouman et al., 2001; Bouman and van Laar, 2006).

\section{Introduction to DSSAT crop models}

The DSSAT software Version 4.5.1.023 (Hoogenboom et al., 2015; www.dssat.net) includes more than 40 crop models which share the same soil water balance, same soil $\mathrm{N}$ balance, and same soil $\mathrm{C}$ balance modules (in that respect, the module approach is very similar to APSIM). The CERES-Maize, CERES-Sorghum, CERES-Millet, CERES-Wheat, CERES-Rice, and CROPGROPeanut models were used in this project. The DSSAT models are described by Jones et al. (2003) and related papers. The CERES-style models use the RUE approach, based on the fraction of light intercepted, RUE, and modifiers of RUE (depending on temperature and $\mathrm{CO}_{2}$; see Boote et al. (2010) for a description of the $\mathrm{CO}_{2}$ modifier on RUE for CERES-style C-3 and C4 crops in DSSAT). The CROPGRO models in DSSAT use leaf-level photosynthesis (based on rubisco kinetics theory) scaled up to canopy assimilation (Boote and Pickering, 1994; Pickering et al., 1995), along with growth and maintenance respiration following the approach of Penning de Vries et al. (1974).

The soil water balance in DSSAT uses the tipping bucket method (Ritchie, 1998). Thus, APSIM and DSSAT have a very similar soil water balance approach (see Boote et al. (2009) and Ritchie (1998) for detailed descriptions of root water uptake, soil evaporation, crop transpiration, and water stress computation). There are several options for evapotranspiration including FAO-56 (Allen et al., 1998), but the Priestley-Taylor approach (1972) was used because of a lack of data on humidity and wind speed. Water stress on photosynthesis (dry matter accumulation) occurs when root water uptake cannot meet transpiration demand.

There are two DSSAT options for soil C balance and N mineralization; GodwinPapran (Godwin and Singh, 1998), and DSSAT-CENTURY (Gijsman et al., 2002), of which the DSSAT-CENTURY option was used for all the DFID project simulations because it is more appropriate for degraded soils and unfertilized conditions. While the soil $\mathrm{N}$ balance and root $\mathrm{N}$ uptake are similar within the DSSAT models, the CERES and CROPGRO modules have different approaches for handling $\mathrm{N}$ stresses in the plant. For a more detailed description of soil-crop $\mathrm{N}$ balance processes, see Godwin and Singh (1998) and Boote et al. (2008), and for information on soil C balance, see Gijsman et al. (2002), Basso et al. (2011), and Porter et al. (2010). Methods for initializing the stable C pool (SOM3) for DSSAT-CENTURY are described by 
Basso et al. (2011) and Porter et al. (2010). A comprehensive evaluation of the CERES-Maize, Wheat, and Rice models is available from Basso et al. (2016).

\section{Experimental data for regions and calibration for distributions of yields within farm surveys}

The regional teams in West Africa, East Africa, South Africa, Southeast Africa, Pakistan, and South India obtained farm survey yield data for selected crops from households in their regions, and matched this with available farm management information, historical weather, soil information, and local cultivars (calibrated from experiments in their regions). Unfortunately, we were lacking knowledge of initial conditions for all survey yield fields including initial inorganic $\mathrm{N}$ and soil water status, and prior crop residue, all of which influence yield levels via $\mathrm{N}$ supply and water supply, especially for low-input farming systems. Furthermore, somewhat generic soils for the sites were used rather than actual observed soil characteristics. Therefore, soil water-holding traits and soil organic $\mathrm{C}$ were not specific to the actual farms.

Despite these deficiencies of information, the teams attempted to mimic the yield distributions present in farmer fields (50-100 farms) substantially by the setting of the stable soil carbon pools for soils used by the two crop models as well as modifying rooting patterns and soil water-holding traits. As pointed out by Godwin and Singh (1998), yield of non-legumes is highly sensitive to initial conditions, particularly initial available N; thus, the adjustments of stable soil organic matter (SOM3) and F-inert to higher than expected values are artefacts of not having the initial conditions and accurate soil information.

\section{Evaluation of Model Sensitivities to $\mathrm{CO}_{2}$, Temperature, Rainfall, and N Factors}

The teams selected representative farms from the "mid-range" within the distribution of farm yields on which to evaluate DSSAT and APSIM model simulations for response to CTWN. The sensitivity ranges for CTWN were 360, 450, 540, 630, and $720 \mathrm{ppm}$ for $\mathrm{CO}_{2} ;-2^{\circ} \mathrm{C}$, ambient, $+2^{\circ} \mathrm{C},+4^{\circ} \mathrm{C},+6^{\circ} \mathrm{C}$, and $+8^{\circ} \mathrm{C}$ for air temperature; $25 \%, 50 \%, 75 \%, 100 \%, 125 \%, 150 \%, 175 \%$, and $200 \%$ ambient for rainfall; and $0,30,60,90,120,150,180$, and $210 \mathrm{~kg} \mathrm{Nha}^{-1}$ of applied N, all done as single-factor responses (limits set following Ruane et al., 2014). Model simulations were conducted for 30-year historical records (historical weather if available or the AgMERRA climate forcing dataset; Ruane et al., 2015). Then, the means of the 30-year results were computed and reported in the graphs that show the responses to CTWN for APSIM and DSSAT. For more details on protocols followed in the AgMIP-DFID modeling, see Thorburn et al. (2015). 


\section{Results and Discussion}

Our approach will be to discuss model sensitivity to $\mathrm{N}$ fertilization, $\mathrm{CO}_{2}$ response, and rainfall separately and, in that order, considered over all the crops because the issues for response to $\mathrm{N}$ fertilizer and rainfall occur and repeat across the crop types, and are often similar for both the APSIM and DSSAT models. The $\mathrm{CO}_{2}$ response is unique as the contrast is mostly $\mathrm{C}-3$ versus $\mathrm{C}-4$ type crops, but the crops/models are similar within C-3 or C-4 crop types. For temperature responses, we follow one crop at a time, discussing model differences in simulated responses at different sites, including a discussion of parameterization that creates model differences for APSIM versus DSSAT. Sometimes regional effects will be highlighted where responses differed by regions created by the local starting point conditions (cool versus warm sites, good versus degraded soils, low-N versus high-N fertilization, or rainfed versus irrigated sites).

\section{Nitrogen Response Depends on SOM Pools and SOM Mineralization}

While the two model systems differed somewhat in responses to $\mathrm{CO}_{2}$, temperature, and rainfall for the different crop types, the most important lesson learned was the need to set soil carbon pools (stable carbon pool, SOM3, for DSSAT-CENTURY, and the inert carbon pool, Finert, for APSIM) in order to mimic reasonable response of non-legumes to $\mathrm{N}$ fertilization for degraded soil conditions. The response to $\mathrm{N}$ fertilization from 0 to $210 \mathrm{~kg} \mathrm{Nha}^{-1}$ in steps of $30 \mathrm{~kg} \mathrm{Nha}^{-1}$ showed that SOM3 and Finert had to be set correctly to mimic the yields obtained for zero $\mathrm{N}$ fertilizer, while the yield levels at the high- $\mathrm{N}$ fertilization represent the genetic potential of the cultivar selected, which is another important but challenging feature to set correctly for the crop models. Note that most farmers in Africa apply little to no $\mathrm{N}$ fertilizer. Setting soil organic $\mathrm{C}$ pools was a problem for all non-legume crops (maize, sorghum, millet, wheat, and rice) because knowledge of initial available inorganic $\mathrm{N}$ and prior crop residue was not available; in addition, the soil organic $\mathrm{C}$ used for the fields was obtained from somewhat generic soils, so even that did not correspond exactly to the real farmer's field.

Getting the $\mathrm{N}$ response correctly, especially the yield at zero $\mathrm{N}$ fertilization, is much more important than the climate response or $\mathrm{CO}_{2}$ response in many cases. The need for correct $\mathrm{N}$ response is important because the teams typically used $\mathrm{N}$ fertilization as one of their first-choice intervention options for improving production. The fraction of stable C (SOM3-CENTURY) was often surprisingly high (up to 0.97), and Finert for APSIM also had to be higher than expected (APSIM modelers suggested a cap of 0.70 for topsoil layers which was bumped up in some cases) when low yields were found to be associated with soils of high soil organic carbon contents. 


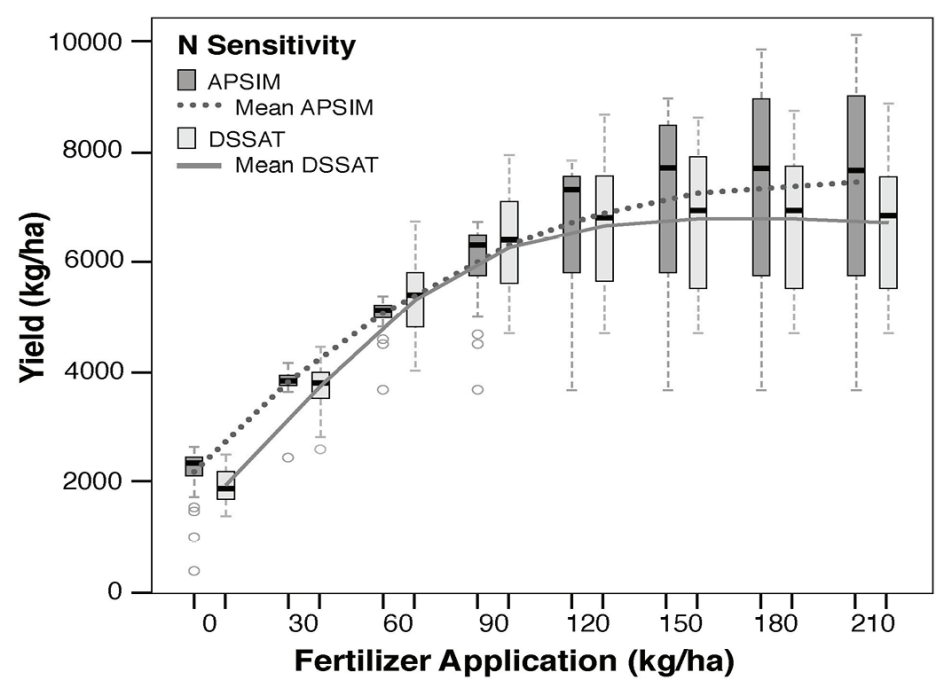

(a)

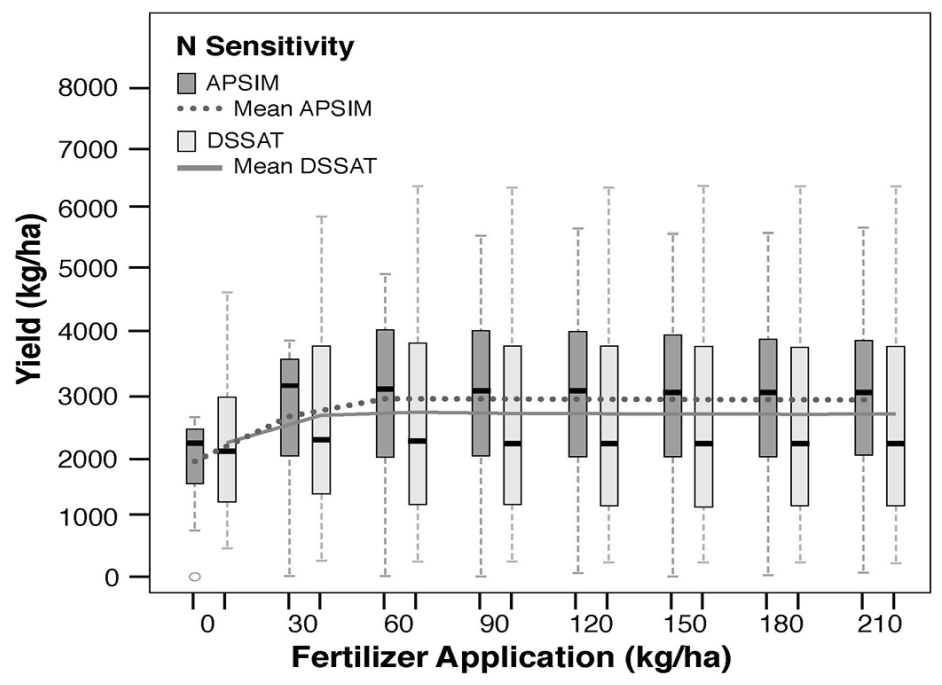

(b)

Fig. 1. Simulated maize yield response to N fertilization for the APSIM- and DSSAT-Maize models under supplemental irrigation in South India (a) and under rainfed conditions in the Republic of South Africa (b), calibrated for high genetic potential yield. The conditions in the Republic of South Africa site are strongly rainfall limited.

Maize grain yield responses to $\mathrm{N}$ fertilization are shown for an irrigated crop in South India (Fig. 1(a)), rainfed crop in the Republic of South Africa (Fig. 1(b)), and for three rainfed sites in Kenya (Fig. 2) where yield potential varies because of elevation-temperature-rainfall, along with native soil fertility variation. The 

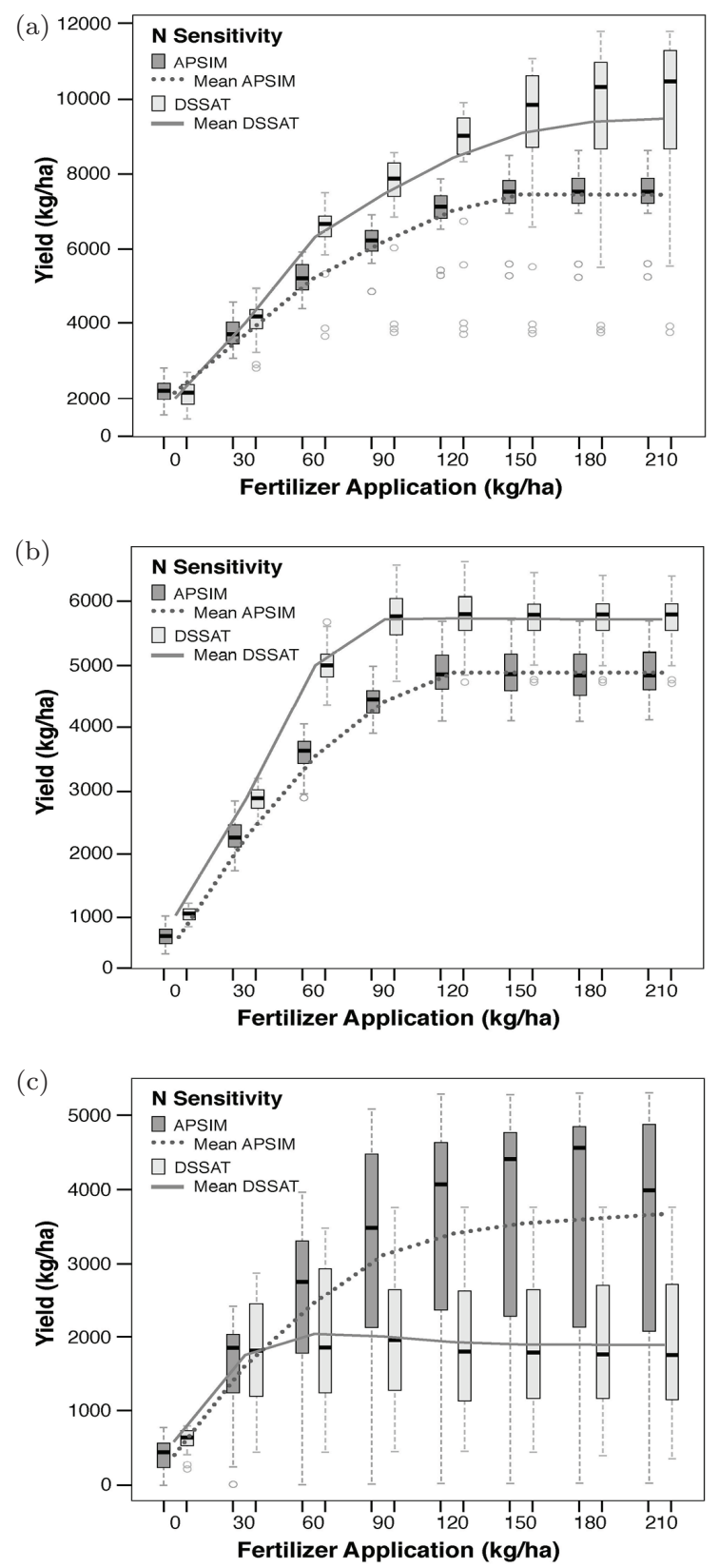

Fig. 2. Simulated maize yield response to $\mathrm{N}$ fertilization under rainfed conditions for APSIM and DSSAT models at high (a), medium (b), and low (c) potential zones varying in elevation in Kenya. The site in the low-potential zone in Kenya is strongly rainfall limited, especially evident for DSSAT. 
simulated grain yield at zero $\mathrm{N}$ fertilization ranges from 500 to $2000 \mathrm{~kg} \mathrm{ha}^{-1}$, being as low as $500 \mathrm{~kg} \mathrm{ha}^{-1}$ at the low-fertility sites such as Kenya (Fig. 2) and West Africa (data not shown). However, this is achieved only after setting a high fraction for stable soil C. The initial response to $\mathrm{N}$ fertilization is linear from 0 to $60 \mathrm{~kg} \mathrm{~N} \mathrm{~kg} \mathrm{ha}^{-1}$ at all sites, including India (Fig. 1), Kenya (Fig. 2), and East, West, and Southeast Africa. In general, the response to $\mathrm{N}$ fertilization is less at rainfall-limited sites (Figs. 1(b) and 2(c)) but greater for irrigated sites (Fig. 1(a), South India) and higher-rainfall sites (Figs. 2(a) and 2(b)). Under water limitation, both the APSIM and DSSAT models show higher year-to-year variability in yield especially at higher $\mathrm{N}$ fertilization levels (Figs. 1(b) and 2(c)). All CTWN simulations were done over 30 years, which is illustrated by the length of the box-and-whisker bars in the figures. The year-to-year variability is smaller for the irrigated crop in South India, although the somewhat higher seasonal variability at high- $\mathrm{N}$ fertilization for the South Indian site could be attributed to the use of supplemental irrigation rather than full irrigation.

The APSIM and DSSAT models responded quite similarly to $\mathrm{N}$ for both wheat and rice in the Indo-Gangetic-Basin (IGB) region of India where both crops are irrigated. The yield was $2000 \mathrm{~kg} \mathrm{ha}^{-1}$ or less for the unfertilized case, with yield increasing asymptotically up to about $150 \mathrm{~kg} \mathrm{Nha}^{-1}$ for wheat (Fig. 3(a)) and up to more than $180 \mathrm{~kg} \mathrm{Nha}^{-1}$ for rice (Fig. 3 b)). The earlier yield plateau and the greater yield variability at high $\mathrm{N}$ for wheat may reflect minor water deficit, as irrigation during the winter dry season may be less than sufficient.

\section{$\mathrm{CO}_{2}$ Response Differs by Crop Type, but Is Also Affected by $\mathrm{N}$ Fertilization}

There are two well-documented crop photosynthesis types, C-3 (wheat, rice, and peanut) versus C-4 (maize, sorghum, and millet), and these two types differ in response to $\mathrm{CO}_{2}$. This pattern is reflected in the $\mathrm{CO}_{2}$ responses of the crop models used in this chapter, with the simulated C-3 crops showing a much higher response than the simulated C-4 crops.

The APSIM and DSSAT models for maize showed small responses to $\mathrm{CO}_{2}$ as expected (Figs. 4 and 5), although APSIM was surprisingly somewhat more responsive than expected as APSIM-Maize has no direct $\mathrm{CO}_{2}$ effect on RUE. However, APSIM-Maize does include enhanced transpiration-use efficiency and $\mathrm{N}$-use efficiency responses with increasing $\mathrm{CO}_{2}$. The TE effect likely applies for the South Indian site (Fig. 4) where the use of supplemental irrigation allowed some water deficit to occur. In addition, the reduction in $\mathrm{N}$ stress with increased $\mathrm{CO}_{2}$ is possible because APSIM-Maize yield response to N (Fig. 1) increased above $180 \mathrm{~kg} \mathrm{ha}^{-1}$ up to $210 \mathrm{~kg} \mathrm{ha}^{-1}$. For the site in the Republic of South Africa (Fig. 5), this comparison 


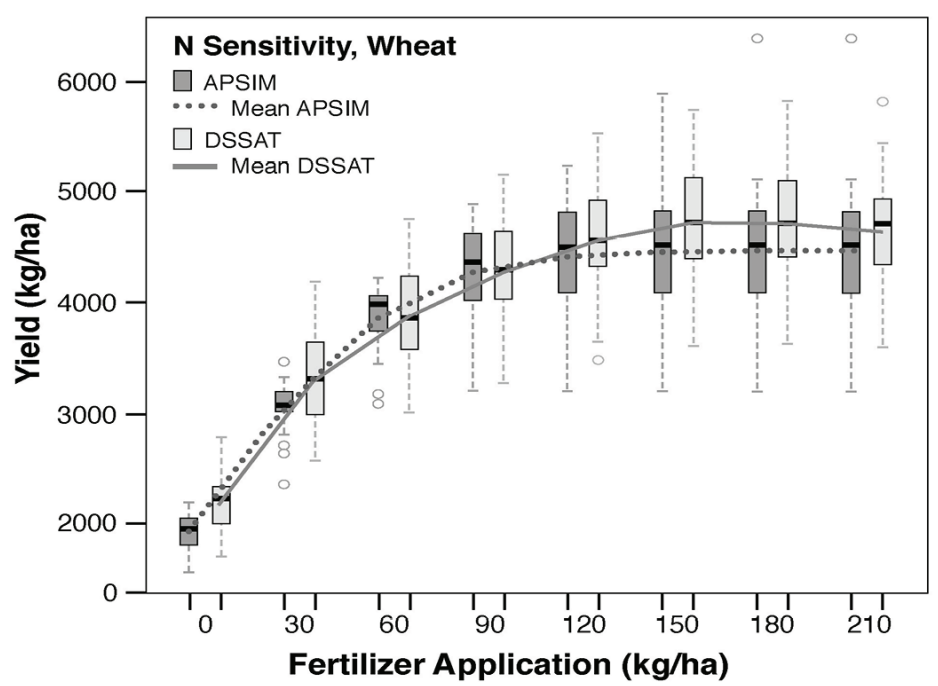

(a)

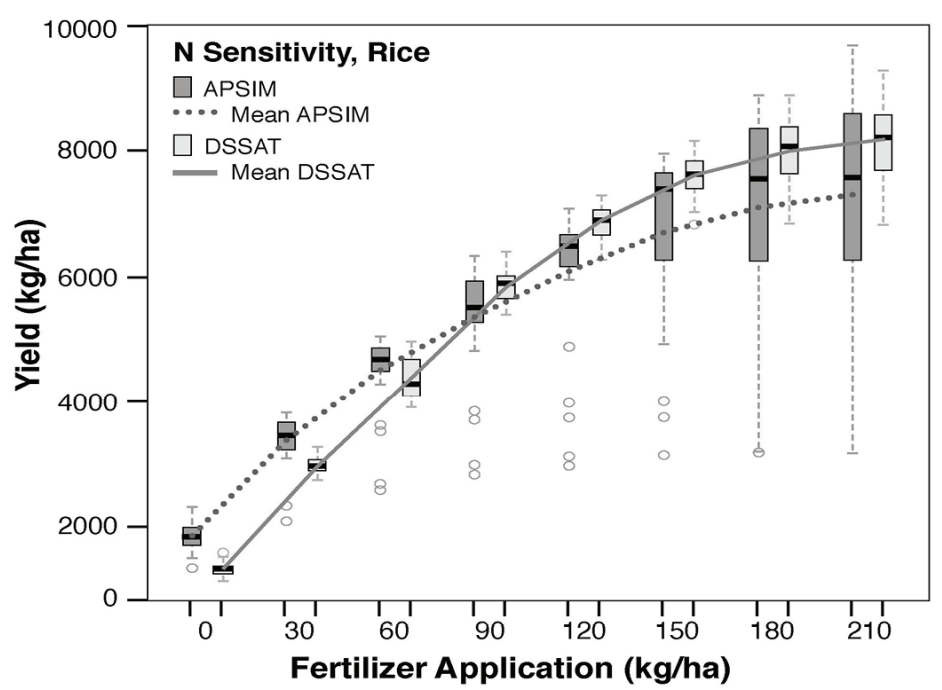

(b)

Fig. 3. Simulated yield response to $\mathrm{N}$ fertilization of APSIM and DSSAT models for irrigated wheat (a) and irrigated rice (b) in the IGB region of India.

repeats, with APSIM-Maize showing more $\mathrm{CO}_{2}$ response than DSSAT, especially at the high $180 \mathrm{~kg} \mathrm{ha}^{-1}$. The South African site is very limited for rainfall; thus, the TE modifier effect clearly must be functioning strongly at high-N fertilization. The severe water limitation for the South African site shows up in the large box-andwhisker bars of the interannual yield variation for both models. 


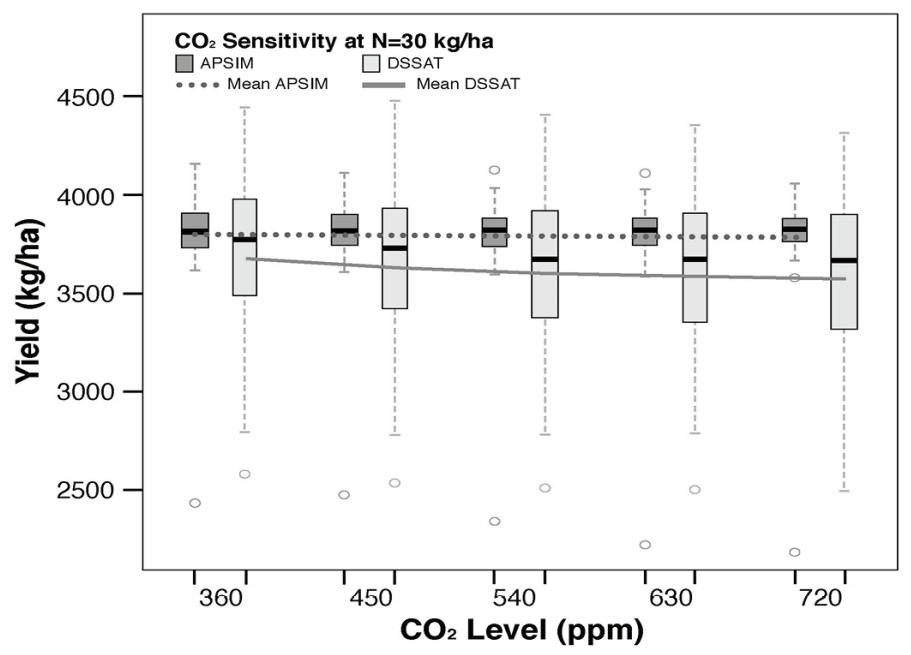

(a)

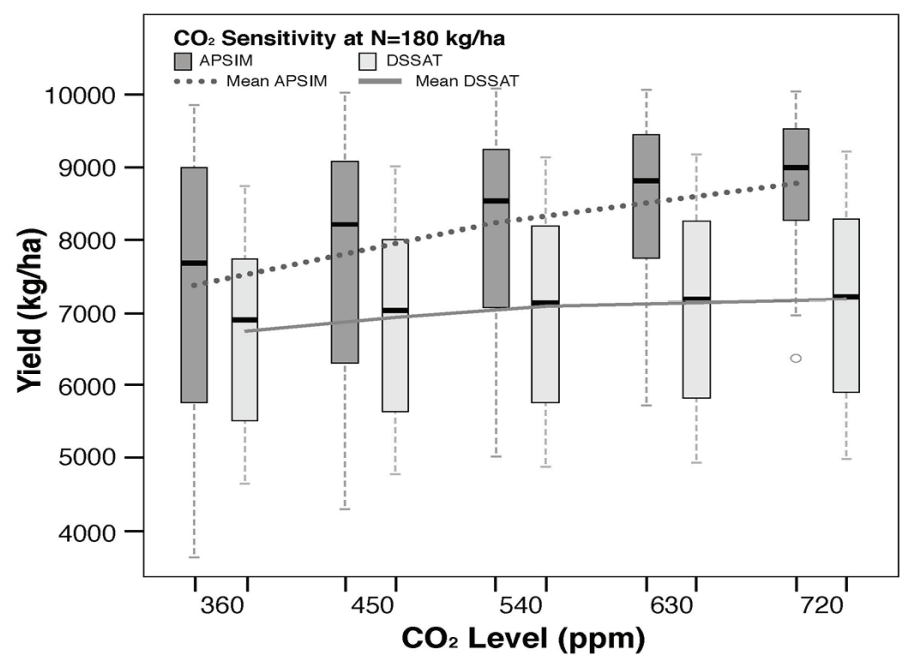

(b)

Fig. 4. Simulated maize yield response to $\mathrm{CO}_{2}(360-720 \mathrm{ppm})$ for APSIM- and DSSAT-Maize models at (a) 30 or (b) $180 \mathrm{~kg} \mathrm{Nha}^{-1}$ in South India, showing lower $\mathrm{CO}_{2}$ response under low-nitrogen fertilization.

For the sorghum models at the rainfed South African site, APSIM and DSSAT showed a very similar response to $\mathrm{CO}_{2}$ as the maize models (Fig. 6). APSIMSorghum had a somewhat higher response to $\mathrm{CO}_{2}$, which is attributed to the TE effect operating in APSIM under these water-limited conditions.

By contrast, for the $\mathrm{C}-3$ crops, the models as expected gave a much higher response to $\mathrm{CO}_{2}$ for wheat and rice than for $\mathrm{C}-4$ maize and sorghum. For these 


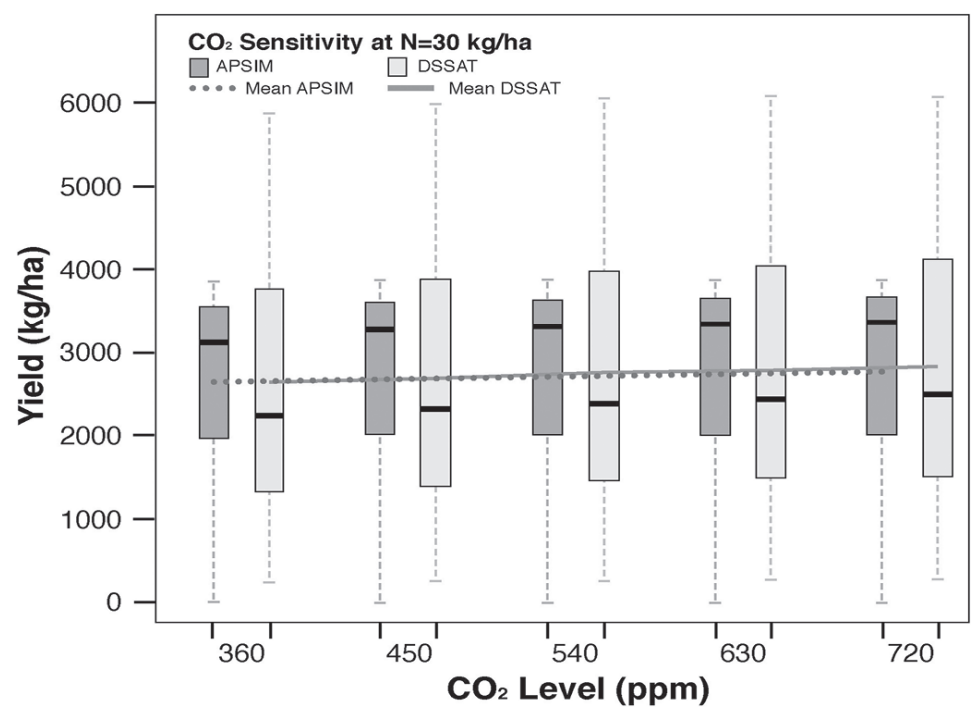

(a)

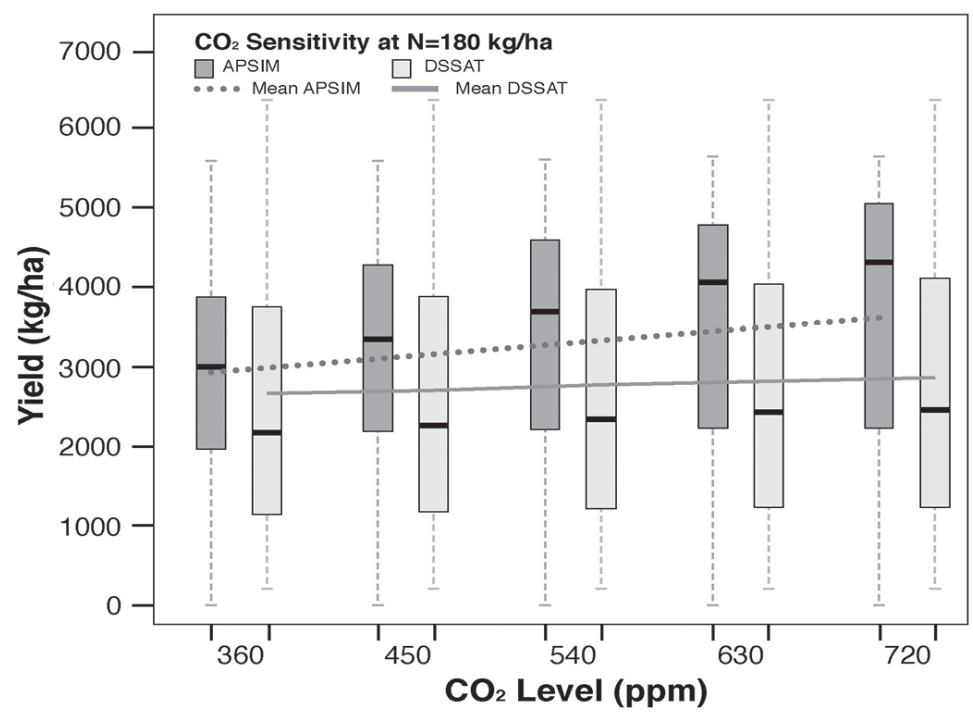

(b)

Fig. 5. Simulated yield response to $\mathrm{CO}_{2}(360-720 \mathrm{ppm})$ for APSIM- and DSSAT-Maize models at (a) 30 or (b) $180 \mathrm{~kg} \mathrm{Nha}^{-1}$ for the rainfed site in the Republic of South Africa.

C-3 crops (wheat and rice), the two models, APSIM and DSSAT, were similar in their $\mathrm{CO}_{2}$ responses. The typical response was a $30 \%$ increase in yield with a $\mathrm{CO}_{2}$ increase from 360 to $720 \mathrm{ppm}$, as illustrated for wheat in Fig. 7, which has also been reported in other AgMIP model evaluations. For both C-3 and C-4 crops, DSSAT 


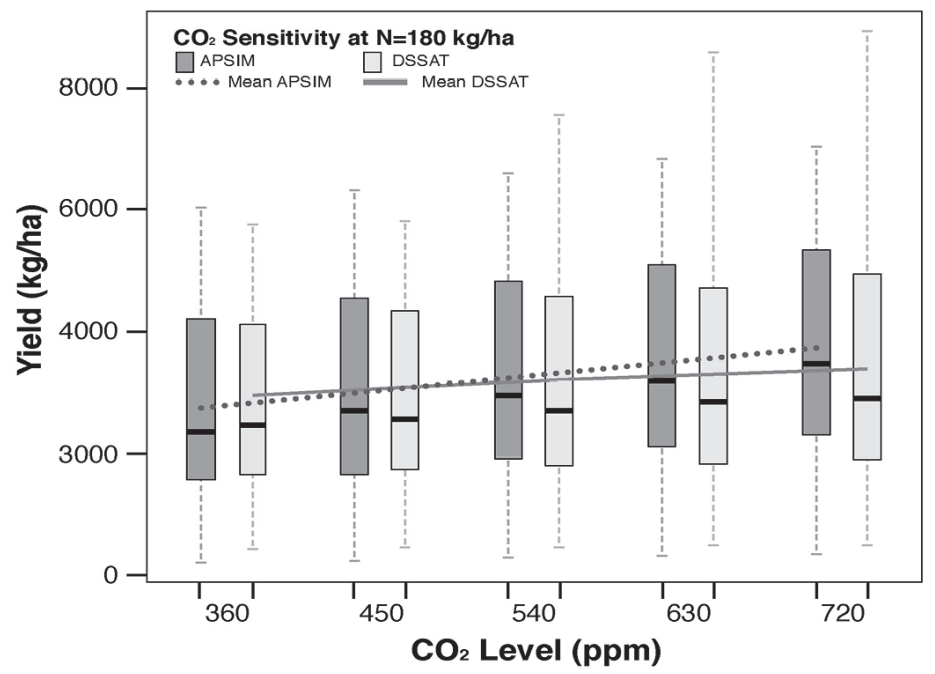

Fig. 6. Simulated yield response to $\mathrm{CO}_{2}(360-720 \mathrm{ppm})$ for APSIM- and DSSAT-Sorghum models at $180 \mathrm{~kg} \mathrm{Nha}^{-1}$ for the rainfed site in the Republic of South Africa.

applies a multiplier on RUE, which then feeds through the system to biomass and yield. DSSAT has a very small effect of elevated $\mathrm{CO}_{2}$ to reduce "hypothetical" stomatal conductance and therefore reduces transpiration (see Boote et al., 2010 for description of the $\mathrm{CO}_{2}$ modifier of transpiration in DSSAT). For C-4 crops, APSIM applies $\mathrm{CO}_{2}$ effect on transpiration water-use efficiency and N-use efficiency, while for C-3 crops, APSIM applies $\mathrm{CO}_{2}$ effects on both RUE and TE.

An important finding is that the simulated response to $\mathrm{CO}_{2}$ shows interaction with $\mathrm{N}$ fertilization, being less under low- $\mathrm{N}$ than under high- $\mathrm{N}$ fertilization (30 versus $180 \mathrm{~kg} \mathrm{Nha}^{-1}$ ), observed for maize, wheat, and rice simulations (rice results not shown) with both DSSAT and APSIM. Examples of this simulated lower response to $\mathrm{CO}_{2}$ at low $\mathrm{N}$ are shown for maize (Figs. 4 and 5) and wheat (Fig. 7), and one can note the contrast between the panels (a) at $30 \mathrm{~kg} \mathrm{Nha}^{-1}$ and the panels (b) at $180 \mathrm{~kg} \mathrm{Nha}^{-1}$. The lower response to $\mathrm{CO}_{2}$ at low-N versus high-N fertilization has been documented in real experiments on rice (Nakagawa et al., 1994; Ziska et al., 1996), so we have confidence in these simulations. The causal factor in the model simulations is that growth and photosynthetic response to $\mathrm{CO}_{2}$ are limited in $\mathrm{N}$-deficient crops because the $\mathrm{N}$ needed for new tissue growth is not available.

\section{Response to Rainfall Depends on Soil Type, Crop Type, and N Fertility}

Response to rainfall will not be discussed for wheat or rice (sites in Pakistan and India), because those two crops are grown with irrigation in those regions. We 


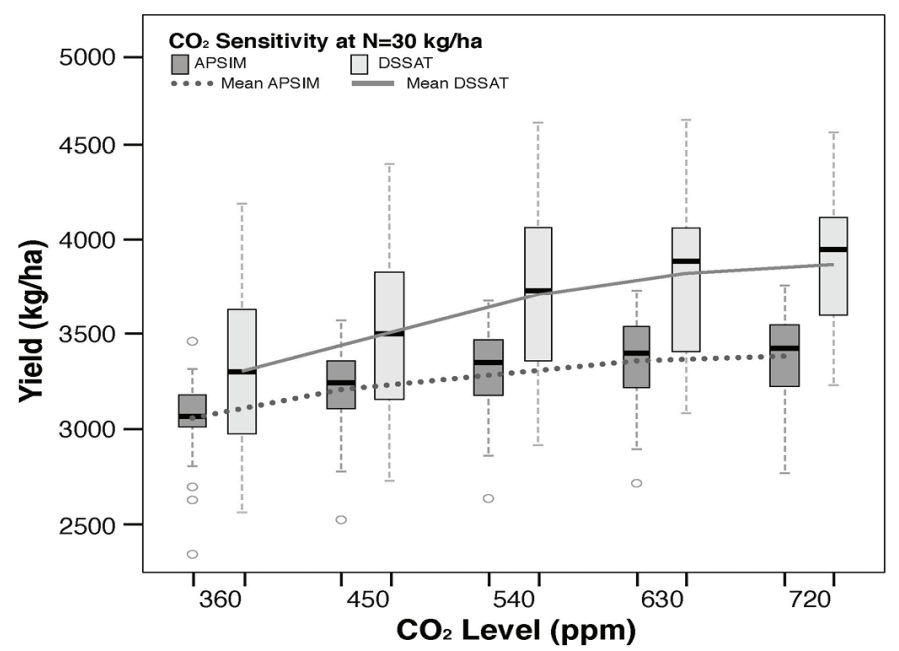

(a)

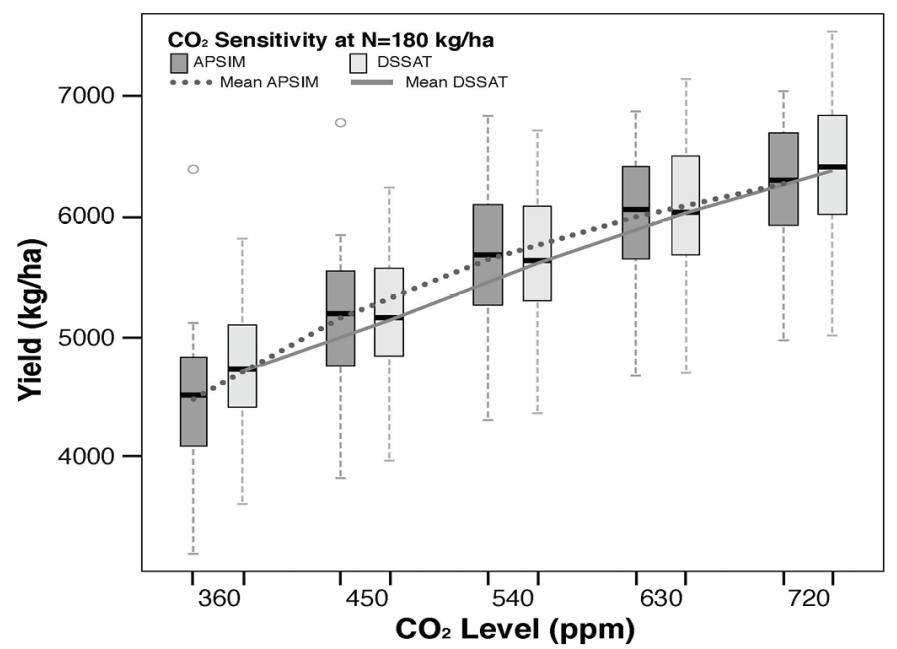

(b)

Fig. 7. Simulated wheat yield response to $\mathrm{CO}_{2}(360-720 \mathrm{ppm})$ for APSIM and DSSAT models at (a) 30 or (b) $180 \mathrm{~kg} \mathrm{Nha}^{-1}$ under irrigation in Northern India, showing lower $\mathrm{CO}_{2}$ response under low-nitrogen fertilization.

will limit our discussion to crops at African sites, which varied considerably in rainfall. Rainfall varies in West Africa going from west to east (being lower in Senegal and higher in Ghana), and rainfall in Kenya varies considerably on a regional basis with elevation. For rainfed sites with low-N fertilization and degraded soils, the yield response to rainfall was relatively small and was less than expected for maize (Fig. 8'a)), millet (Fig. 9(b)), and sorghum (not shown). For these sites, 


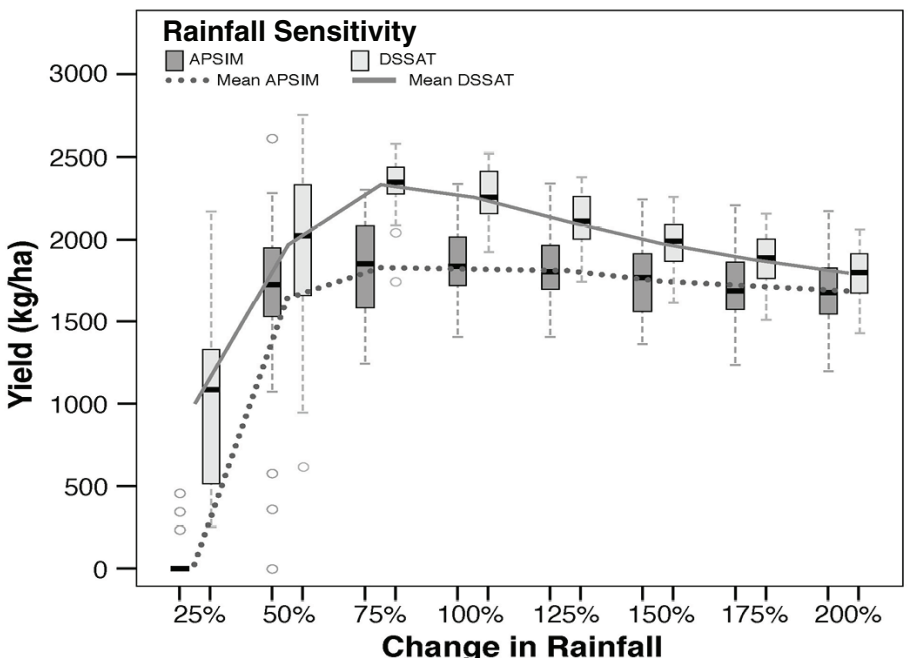

(a)

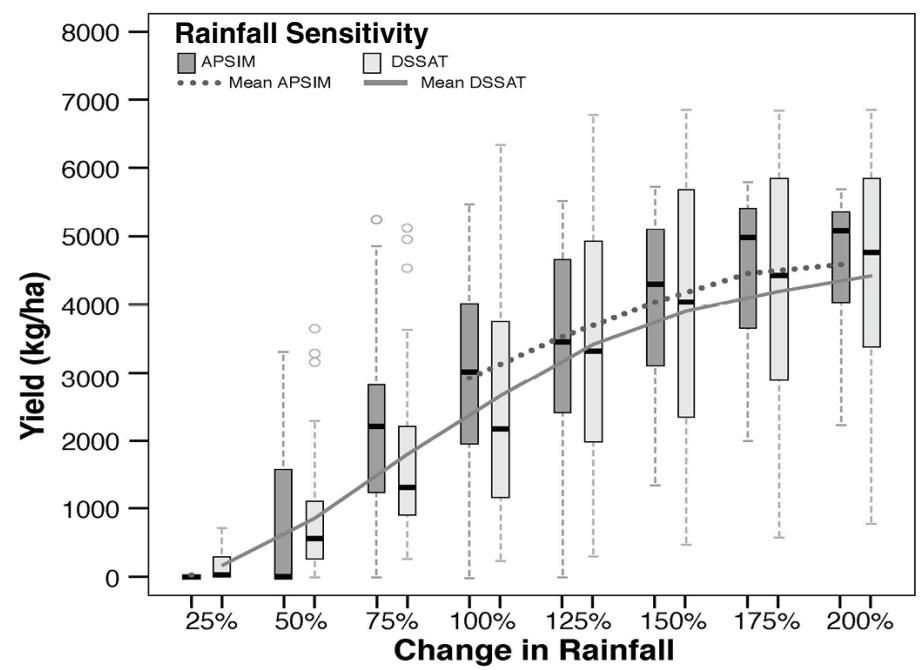

(b)

Fig. 8. Maize yield response to rainfall variation (25-200\% of ambient) in medium-yield potential zone in Kenya with poorly fertilized, degraded soils (a), and South Africa with well-fertilized conditions on good soils (b).

$\mathrm{N}$ was so limiting that the leaf area index was low, which created low transpiration demand for water.

We believe that the models are right in this respect from a theory standpoint, although serious field research investigation is needed to confirm this. Field experiments on maize and cowpea in Limpopo Province (data of J. Dimes, 


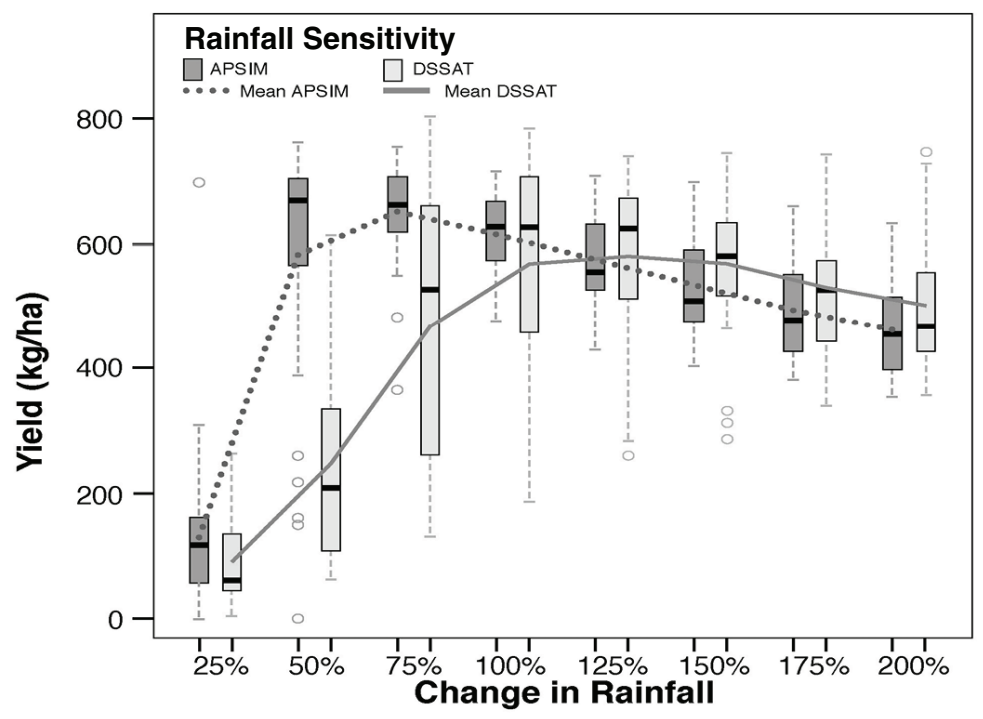

(a)

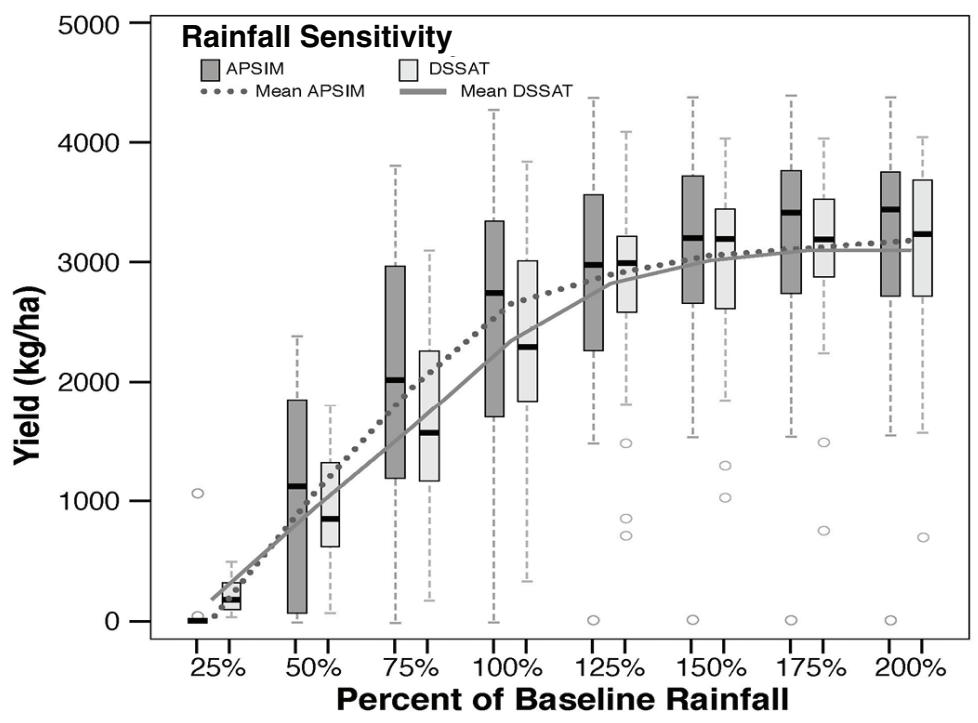

(b)

Fig. 9. Simulated yield response to rainfall variation for (a) the APSIM- and DSSAT-Millet models at the Nioro site in Senegal with no fertilizer on a degraded soil and (b) the APSIM- and DSSAT-Sorghum models at the Heilbron site in the Republic of South Africa with high-N fertilization on a fertile soil. 
Proceedings of Challenge Program for Water and Food, Addis Ababa) showed that the APSIM model got the above-ground yield correct with good agreement with soil water profiles across the crop cycle. Field experiments on groundnut in northern Ghana also confirmed DSSAT simulations of soil water profiles versus observed soil profiles with correct above-ground biomass simulations (Naab et al., 2004).

For the infertile sites in West Africa, East Africa, and Southeast Africa, simulated maizef yield was often somewhat reduced when rainfall was increased above ambient (100\% case), which in the models is attributed to the leaching of mineralized $\mathrm{N}$ from the soil and loss of $\mathrm{N}$ for the maize crop uptake (see Fig. 8(a), example for medium-potential zone in Kenya). This N-leaching effect, e.g., a reduced yield at higher rainfall under no $\mathrm{N}$ fertilization, was repeated for millet in West Africa as well (Fig. 9'a)).

In the Republic of South Africa, where rainfall is lower but soils more fertile (and with higher $\mathrm{N}$ fertilization), the maize yield increases strongly with increased rainfall (see Fig. 8(b)). We had expected to see differences between APSIM and DSSAT because of the differences in transpiration methodology (APSIM using the TE method, and DSSAT using the Priestley-Taylor method). Nevertheless, the differences between the models for maize yield response to rainfall were small (Fig. 8'b)).

The two models differ for rainfall response of millet in Senegal, indicating more water deficit for the DSSAT-Millet model than the APSIM-Millet model (Fig. 9'a)). The two models have different methods for water uptake as well as crop evapotranspiration, which could be a cause. However, both millet models show a declining yield with higher rainfall under zero $\mathrm{N}$ fertilization associated with $\mathrm{N}$ leaching, similar to that observed for the maize rainfall response under low-N fertilization (Fig. 8'a)). The APSIM and DSSAT sorghum models, by contrast, did not show a differential response to rainfall for the Republic of South Africa site which was well fertilized on a fertile soil (Fig. 9 $(b)$ ). Both models showed strong sensitivity to rainfall for this rainfall-limited but well-fertilized site.

It appears that the interactive effect of $\mathrm{N}$ fertilization and rainfall response of the millet models is similar to simulated interaction of rainfall response and $\mathrm{N}$ fertilization for the maize models. This finding of the interactive effects of rainfall and $\mathrm{N}$ fertilization has important implications for climate impact assessment. Model intercomparisons by the AgMIP low-input agriculture group (Falconnier et al., 2019) confirm that this interaction effect of $\mathrm{N}$ fertilization with $\mathrm{CO}_{2}$ response and rainfall response occurs for simulations of nearly all maize models, with the exception of a few maize models that lack daily $N$ simulation dynamics.

For sensitivity to rainfall, the APSIM and DSSAT peanut models clearly have different responses (Fig. 10). This is perhaps not surprising as the two models have 


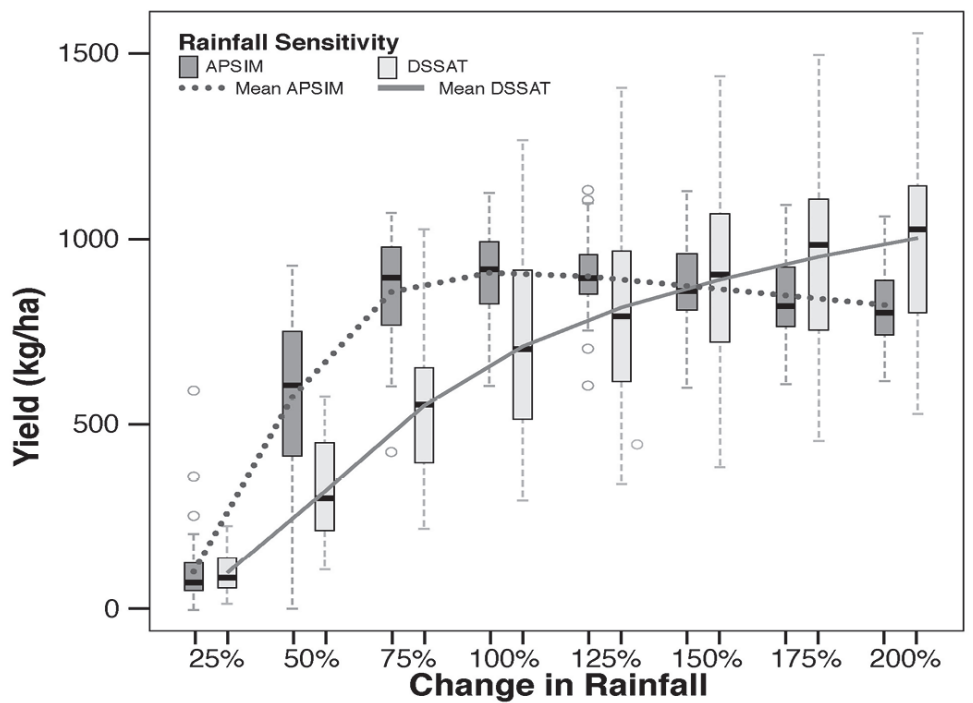

Fig. 10. Peanut seed yield response to rainfall simulated by the APSIM-Peanut and DSSATCROPGRO-Peanut models for a rainfed site in Nioro, Senegal.

very different methods for evapotranspiration (TE method) and soil water uptake. However, we are uncertain as to which model is right and that will await testing against soil water extraction and dry matter growth under water-limited conditions, where growth and soil water contents are measured.

\section{APSIM and DSSAT Models for Same Crops May Differ in Temperature Responses Depending on Model Parameterization}

Understanding model differences in response to temperature requires that we know the parameterization of the models for various growth processes. Crop model parameterization is individualized for each different crop model. Therefore, we will discuss this by individual crops. In addition, our knowledge of and experience in testing models for parameterization of the effects of supra-optimum and elevated extreme temperatures are sparse because of limited data from experiments conducted at elevated temperature conditions. It is important to appreciate that temperature effects on grain yield can result from multiple sources of temperature effects on the following processes: rate of leaf appearance, rate of reproductive progression, leaf area expansion, assimilation (RUE modifier), grain set, and rate of grain growth. The latter three are most likely the primary causes. In addition, there may be effects of temperature on the rate of $\mathrm{N}$ mineralization from SOM. 
Table 1. Cardinal temperature parameterization for temperature-dependent processes for the APSIM- and DSSAT-Maize models.

\begin{tabular}{|c|c|c|c|c|}
\hline Model and Process & Tbase & Topt1 & Topt2 & Tfail \\
\hline \multicolumn{5}{|c|}{${ }^{\circ} \mathrm{C}$} \\
\hline \multicolumn{5}{|l|}{ APSIM } \\
\hline V \& R stage & *(see below) & 34.0 & 34.0 & 44.0 \\
\hline RUE & 8.0 & 15.0 & 35.0 & 50.0 \\
\hline Grain \# Set & **(see below) & & & \\
\hline Grain GR (RGFIL) & 6.0 & 22.0 & 30.0 & 56.0 \\
\hline \multicolumn{5}{|l|}{ DSSAT (all on Tmean) } \\
\hline V \& R stage & 8.0 & 34.0 & 34.0 & \\
\hline RUE (PRFTC) & 6.2 & 16.5 & 33.0 & 44.0 \\
\hline Grain \# Set & & o sensiti & & \\
\hline Grain GR (RGFIL) & 5.5 & 16.0 & 27.0 & 35.0 \\
\hline \multicolumn{5}{|c|}{$\begin{array}{l}\text { Note: * Leaf appearance and reproductive progression (degree day accumulation) } \\
\text { for APSIM-Maize follow a broken stick with a Tb of } 0^{\circ} \mathrm{C}(0.0 \text { rate), relative rate } \\
\text { of } 0.38 \text { at } 18^{\circ} \mathrm{C} \text {, relative rate of } 0.69 \text { at } 26^{\circ} \mathrm{C} \text {, optimum rate of } 1.00 \text { (26 GDD) at } \\
34^{\circ} \mathrm{C} \text {, and relative rate of } 0.00 \text { at } 44^{\circ} \mathrm{C} \text {, and then compute average rate over eight } \\
3 \text {-hour periods based on Tmax and Tmin (do not use Tmean). } \\
{ }^{* *} \text { Grain set reduced if Tmax above } 38 \mathrm{C} \text { during time from flag leaf to time of } \\
\text { grain-set. }\end{array}$} \\
\hline
\end{tabular}

\section{Maize}

While APSIM-Maize originally derived from an older version of DSSAT-CERESMaize (changes began nearly 30 years ago by Carberry et al. (1989)), the two models have evolved over time to have different parameterizations for temperature effects on the rate of life cycle progress, radiation-use efficiency, and grain-filling rate (summarized in Table 1). The DSSAT-CERES-Maize model parameterizations for RUE and especially for single-grain growth rate are more sensitive to elevated temperature (see lower Topt 2 for CERES-Maize), which probably accounts for the greater sensitivity of CERES-Maize grain yield to temperature increase as seen in Fig. 11 for the well-fertilized, irrigated site in India.

CERES-Maize sensitivity of RUE and RGFIL (rate of single-grain growth) to temperature (Table 1) was re-parameterized by Boote (unpublished communication, 2011) for use with Global Futures simulations of climate impacts on maize, in part because the prior model version created during a "modularization era" in early 2000s had no reduction of RUE or RGFIL at elevated temperatures. The original CERESMaize prior to 2000 did have elevated temperature effects on RUE and RGFIL in the source code, but during the "modularization era" the coefficients were removed to become external "read-in" parameters, that were not correctly re-parameterized. At that time, there were few existing studies at elevated temperature on maize for 


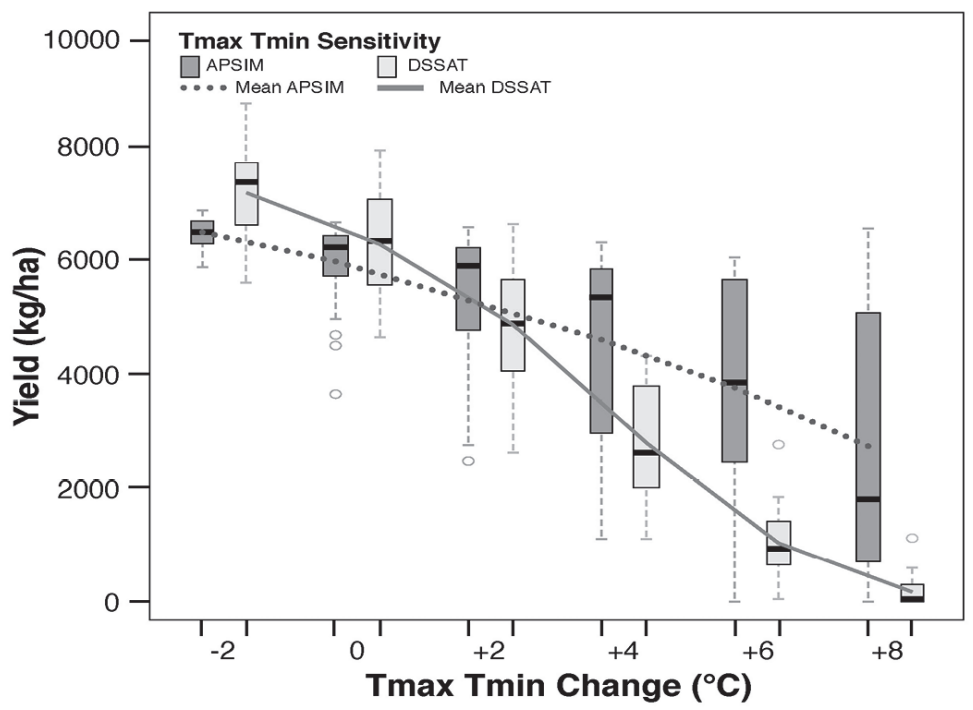

Fig. 11. Simulated yield response to temperature variation for the APSIM- and DSSAT-Maize models in South India (a warm site).

parameterizing these functions. Since then, experiments at elevated temperature have been conducted by Rattalino-Edreira et al. (2011), Lizaso et al. (2017, 2018), and others.

In addition, the two models have different soil organic carbon modules, with different assumptions about the pools of SOM available for $\mathrm{N}$ mineralization and different temperature parameterizations of that process. The temperature parameterization of soil organic $\mathrm{C}$ decomposition in APSIM is carried over from older versions of CERES-Maize that used DSSAT's Godwin-Papran function (Godwin and Singh, 1998). However, the DSSAT-CERES-Maize for all the DFID-funded simulations used the CENTURY soil C module that has a different temperature parameterization from APSIM and different also from the DSSAT's Godwin-Papran function. For additional information, see Bassu et al. (2014) for intercomparison of multiple maize models for sensitivity response of yield to temperature, $\mathrm{CO}_{2}$, and rainfall.

In general, rising temperature $\left(2^{\circ} \mathrm{C}, 4^{\circ} \mathrm{C}, 6^{\circ} \mathrm{C}\right.$, or $8^{\circ} \mathrm{C}$ above ambient in CTWN) reduced the yield for both maize models at most sites including South India (Fig. 11), consistent with a shorter crop life cycle, a shorter grain-filling duration, and a small reduction in RUE. In addition, there is a reduction in grain growth rate at high temperatures for both models, but the DSSAT-CERES-Maize model has a stronger reduction in grain growth rate (RGFIL in Table 1), thus causing the model to be more sensitive than APSIM-Maize to high temperature. Figure 11 illustrates this temperature sensitivity for an already warm site in South India. The greater sensitivity to 
rising temperature of RUE and especially the grain-filling rate for DSSAT-CERESMaize (Table 1) are sufficient explanations for the stronger reduction in yield simulations with DSSAT-Maize.

The sites in Kenya were relatively cool, and are described as high-, medium-, and low-potential zones, varying from cool to moderate to warm temperature with elevation change, along with modest to low rainfall with the same elevation change. APSIM and DSSAT showed different response patterns to temperature for these three zones in Kenya (Fig. 12). We think this is conditioned by the fact that temperatures are cool in all three zones in Kenya, but especially the high-potential zone is cold, where an increase in temperature improved yield of APSIM up to $+4^{\circ} \mathrm{C}$, whereas DSSAT only increased yield up to the $+2^{\circ} \mathrm{C}$ temperature with a considerable decrease at higher temperatures.

These responses are associated with different parameterizations of the two maize models (Table 1), with major differences in the temperature parameters for rate of grain growth. DSSAT has a reduction beginning at $27^{\circ} \mathrm{C}$, with grain growth failure at $35^{\circ} \mathrm{C}$, while APSIM has a reduction beginning at $30^{\circ} \mathrm{C}$ and grain growth failure at $56^{\circ} \mathrm{C}$. The grain growth rate of the two models is also sensitive at the low end, with APSIM being reduced below $22^{\circ} \mathrm{C}$, while DSSAT's grain growth rate reduced below $16^{\circ} \mathrm{C}$. The parameterization differences are the primary reasons for differences, causing APSIM to be very sensitive to cool temperatures during grain filling (see sharp drop at low temperature), but causing DSSAT to be more sensitive at high temperatures.

In addition, there are also differences in the temperature parameterization for RUE with DSSAT being reduced sooner at a high temperature; DSSAT's RUE is reduced above $33^{\circ} \mathrm{C}$ mean daytime temperature and failure at $44^{\circ} \mathrm{C}$, while APSIM's RUE is reduced above $35^{\circ} \mathrm{C}$ and failure at $50^{\circ} \mathrm{C}$. The RUE effect is minor in part because the mean daytime temperature is rarely above $33^{\circ} \mathrm{C}$, except at the high end of the temperature sensitivity response. There is one additional causal factor, which is that the two models have different temperature parameterizations for soil organic $\mathrm{C}$ mineralization. APSIM uses its own soil organic $\mathrm{C}$ mineralization equations, whereas DSSAT in these studies used the CENTURY organic $\mathrm{C}$ module. The two SOC modules have different temperature functions.

\section{Sorghum and millet}

APSIM-Sorghum has been extensively tested in Northern Australia and Central Queensland, and APSIM-Millet was developed in Rajasthan, India, and tested in West Africa. The DSSAT-Sorghum model was reevaluated and improved for its temperature sensitivities against real data by Singh et al. (2014). However, the DSSAT-Millet model version used in this study had not been widely tested. 

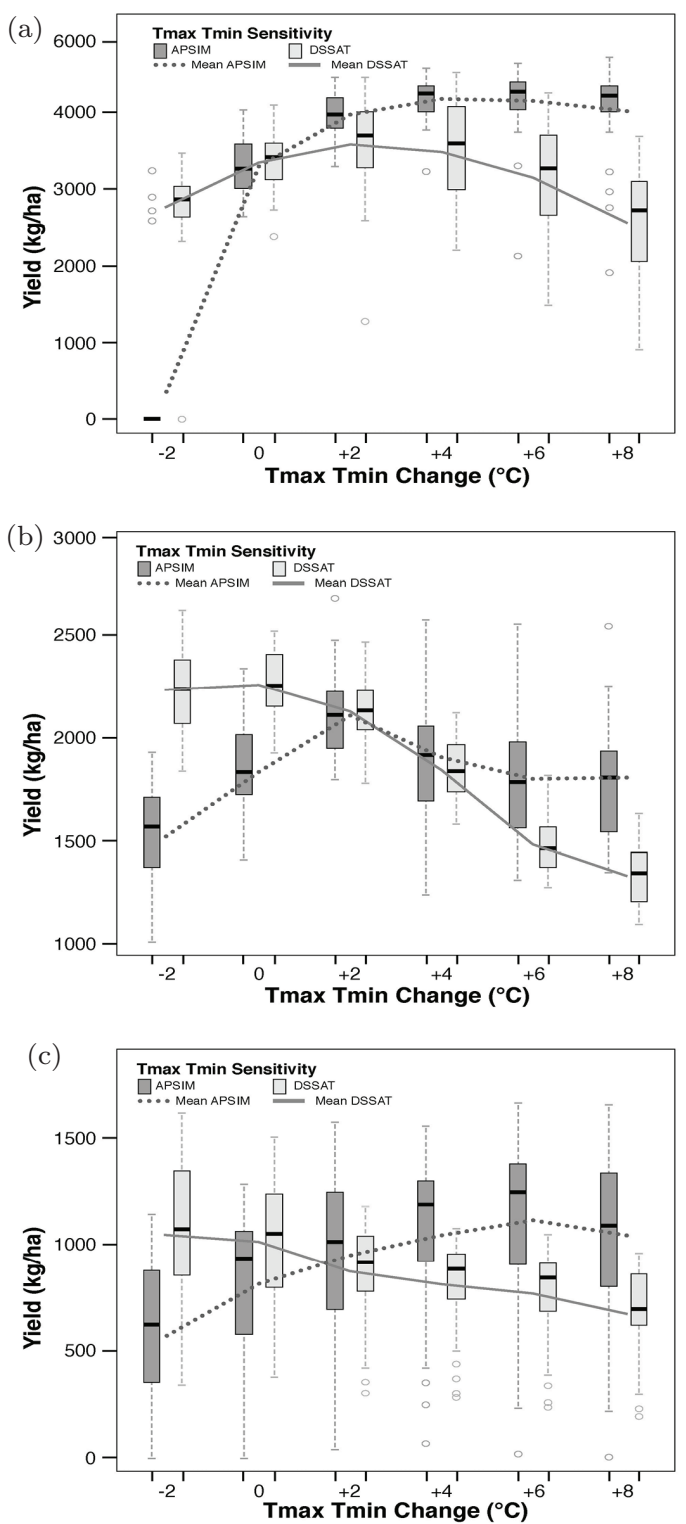

Fig. 12. Simulated yield response to temperature variation for APSIM- and DSSAT-Maize models at high (a), medium (b), and low (c) potential zones varying in elevation in Kenya. Sites vary in temperature and rainfall, being cooler for the high-potential site and warmer for the low-potential site. The $\mathrm{N}$ fertilization rate was 80,40 , and $20 \mathrm{~kg} \mathrm{Nha}^{-1}$ for the high-, medium-, and low-potential sites, respectively. 
For the Republic of South Africa, Heilbron site, the temperature sensitivities of APSIM-Sorghum and DSSAT-Sorghum appear to be very similar to each other (Fig. 13 a)). The models appear to have similar temperature sensitivities, with a quadratic (parabolic) response showing an optimum production at $+2^{\circ} \mathrm{C}$. Note that this region in the Republic of South Africa is relatively cool because of its elevation.

The two millet models differed slightly in their temperature response at the Nioro site in Senegal, with CERES-Millet showing a gentle optimum at $+2^{\circ} \mathrm{C}$, while APSIM-Millet showed almost no sensitivity to temperature, with a very slight decline from $-2^{\circ} \mathrm{C}$ to the highest $+8^{\circ} \mathrm{C}$ temperature (Fig. 13(b)). Note that the yield levels of sorghum in South Africa are much higher than the yields of millet in Senegal. There are several reasons, such as sorghum being more productive than millet and the South African site being well fertilized compared to no fertilization in Senegal. In addition, the South African site is cooler than Senegal.

\section{Wheat}

The DSSAT-CERES-Wheat model has temperature parameterizations on development, assimilation, and grain growth rate typical of C-3 cool season cereals. It appears that the APSIM-Wheat is parameterized very similarly to DSSAT Wheat, because the sensitivity to temperature is quite similar for the two models (Fig. 14), showing reduction in grain yield with any temperature rise above ambient in Pakistan and Northern India (both sites are already quite warm). The optimum temperature for RUE in the two models is $10-25^{\circ} \mathrm{C}$, with reductions below $10^{\circ} \mathrm{C}$, and reductions above $25^{\circ} \mathrm{C}$, towards zero RUE at $35^{\circ} \mathrm{C}$ mean temperature. The temperature parameterization of the two wheat models for reproductive progression and rate of grain filling is also important for yield response.

\section{Rice}

The two rice models are quite different in their heritage, with CERES-Rice somewhat patterned after the style of the CERES models, while the APSIM-ORYZA model is the ORYZA-2000 model brought into the APSIM system, complete with temperature parameterization developed by the ORYZA modelers at IRRI (Bouman et al., 2001). ORYZA was derived from the Dutch SUCROS model, and is based on leaf photosynthesis (Bouman and van Laar, 2006), whereas CERES-Rice is based on RUE. Figure 15 illustrates that yield of the two models is strongly affected by rising temperature above ambient in Northern India (an already warm region), but the response shapes are different, in part because the APSIM-ORYZA model actually slows its life cycle as temperature gets very hot (which causes the unusual plateau between +6 and $+8^{\circ} \mathrm{C}$ ). Unpublished evaluation of these models (Boote, 


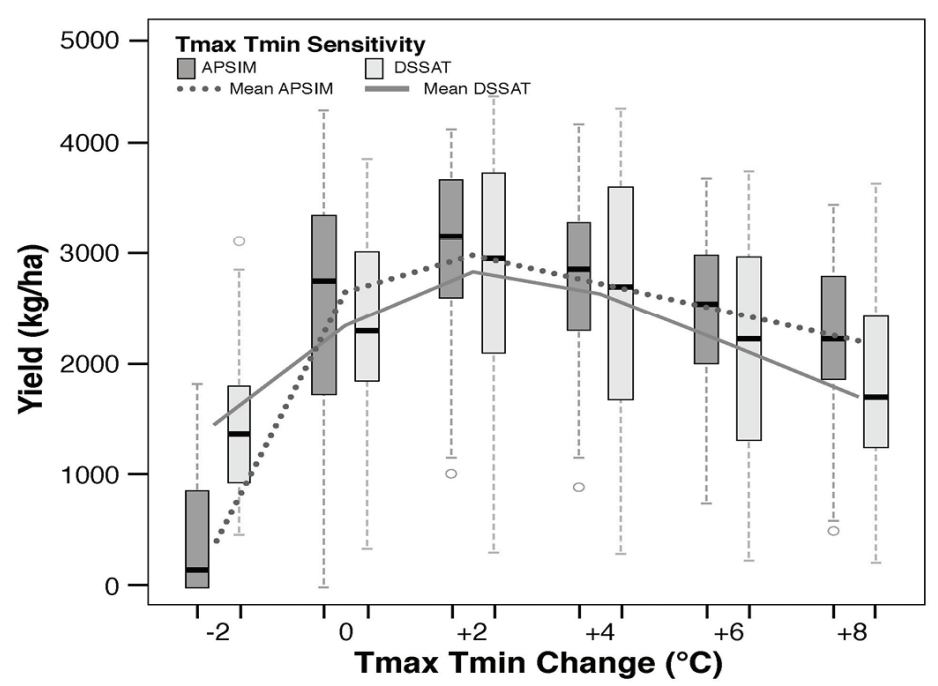

(a)

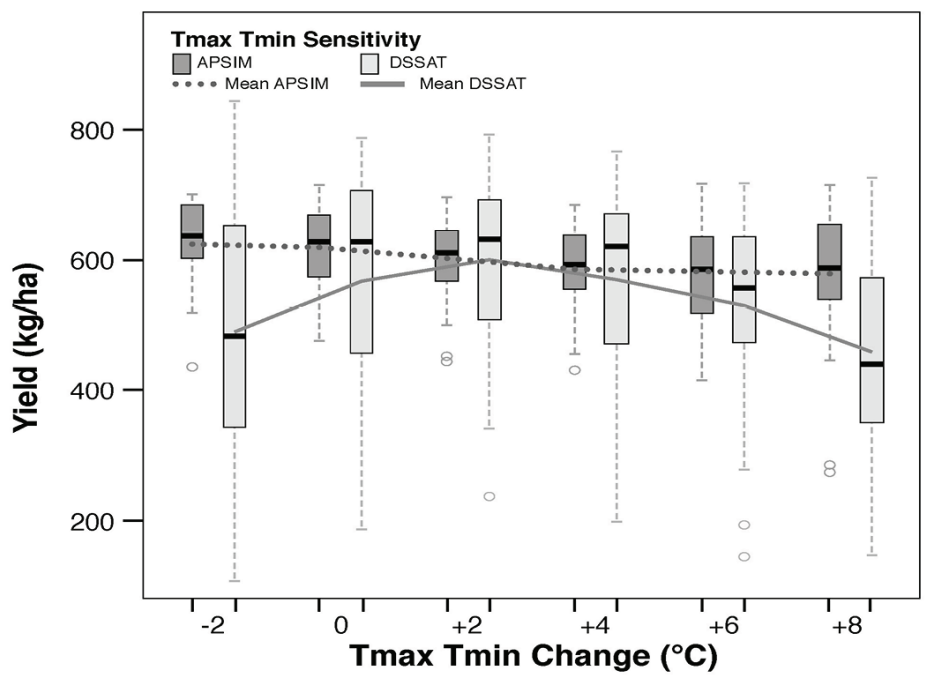

(b)

Fig. 13. Simulated yield response to temperature for (a) APSIM- and DSSAT-Sorghum models at the Heilbron site in the Republic of South Africa and (b) APSIM- and DSSAT-Millet models at the Nioro site in Senegal.

unpublished communication, 2019) against observed data on rice yield response to elevated temperature indicates that the reduction in observed yield with rising temperature (Baker et al., 1992a, 1992b) is as strong as predicted by these models. 


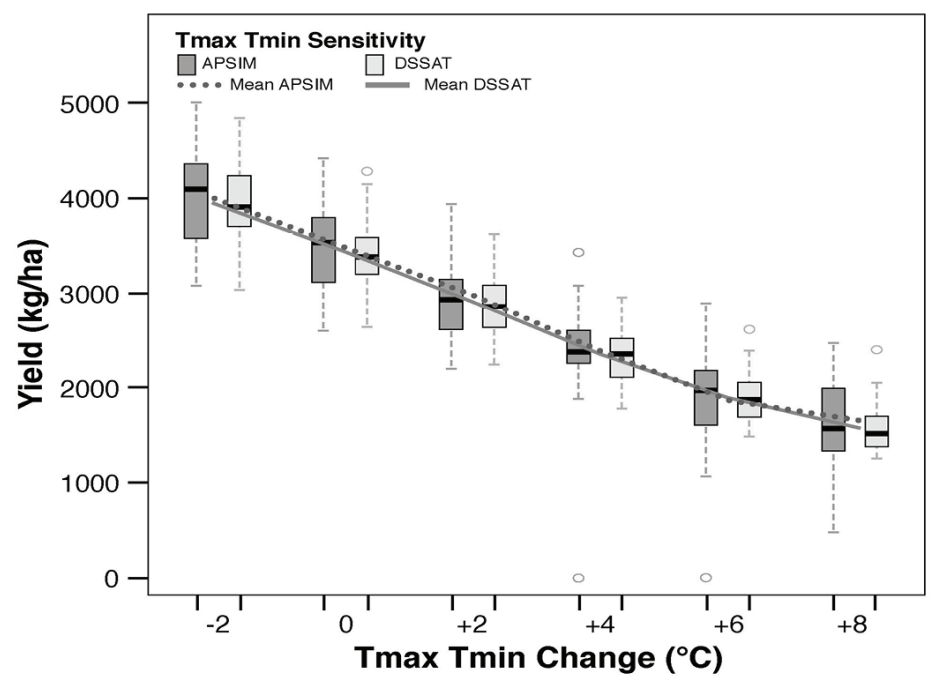

(a)

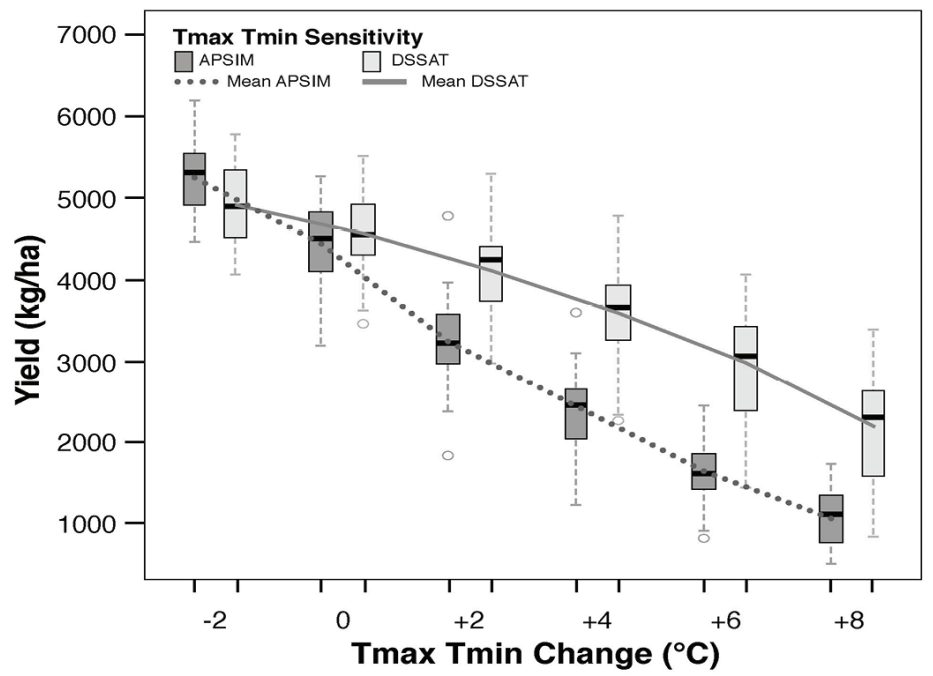

(b)

Fig. 14. Wheat yield response to temperature change, simulated by APSIM and DSSAT models, showing reduction in grain yield with temperature rise above ambient in Pakistan (a) and Northern India (b).

\section{Peanut}

The CROPGRO-Peanut model is different from the other DSSAT models described so far, and it is also different from the APSIM-Peanut model. The CROPGROPeanut model in DSSAT is based on leaf-to-canopy assimilation approach using 


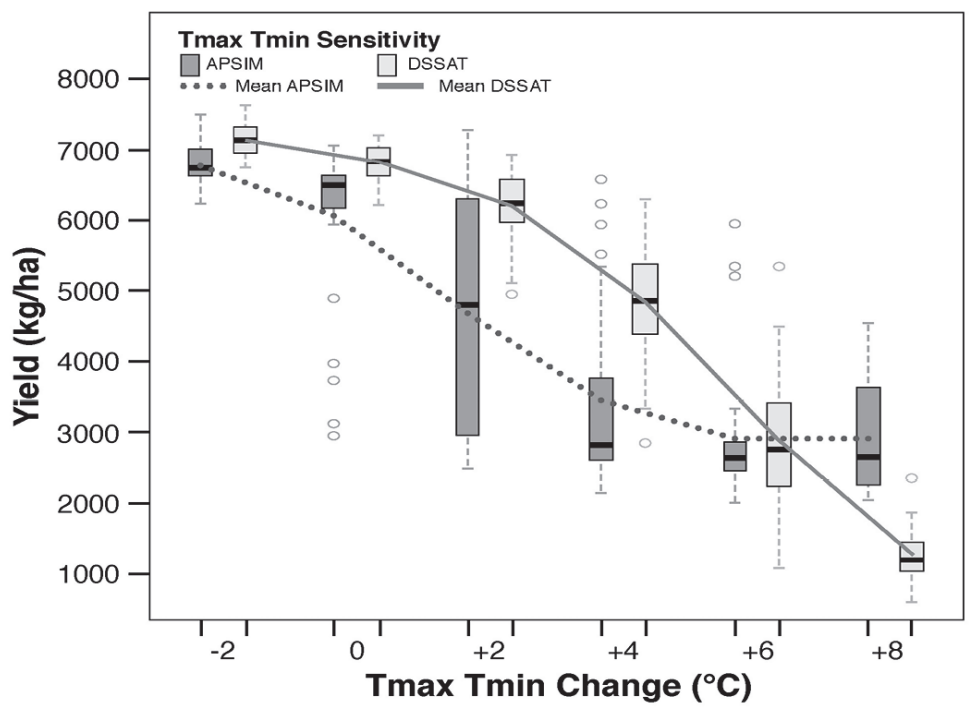

Fig. 15. Rice yield simulated by APSIM-ORYZA and DSSAT-CERES-Rice models, showing reduction in yield with temperature rise above ambient in Northern India.

hourly temperature for photosynthesis and has temperature effects on setting of seed cohorts and single-seed growth. The APSIM-Peanut model is RUE based and predicts seed mass growth up to final yield based on rate of change of seed harvest index (which is sensitive to water, $\mathrm{N}$, and temperature stresses).

Temperature parameterization of the two models is certainly quite different. APSIM peanut has optimum RUE between $21^{\circ} \mathrm{C}$ and $30^{\circ} \mathrm{C}$ mean daily temperature, with reduction to zero from 21 to $10^{\circ} \mathrm{C}$, and reduction to zero going from $30^{\circ} \mathrm{C}$ to $40^{\circ} \mathrm{C}$. CROPGRO Peanut has a base temperature for leaf photosynthesis of $8^{\circ} \mathrm{C}$, but its optimum is $40^{\circ} \mathrm{C}$. DSSAT-CROPGRO-Peanut has temperature functions that affect pod addition (optimum between $23.5^{\circ} \mathrm{C}$ and $26^{\circ} \mathrm{C}$, with parabolic reduction from $26.5^{\circ} \mathrm{C}$ to $40^{\circ} \mathrm{C}$ ) and seed growth rate (optimum at $23.5^{\circ} \mathrm{C}$, parabolic reduction from $23.5^{\circ} \mathrm{C}$ to $41^{\circ} \mathrm{C}$ ). We have good confidence in the CROPGROPeanut functions, as the model was shown to perform well against the elevated temperature data of Prasad et al. (2003) as reported by Boote et al. (2010, 2018). APSIM-Peanut has unknown sensitivity of temperature effects on partitioning to pod, so yield decline may be an outcome of temperature effect on life cycle and RUE.

The two models differ in their sensitivity to temperature at the Nioro site, Senegal. The DSSAT-CROPGRO-Peanut model is more sensitive to elevated temperature than APSIM (Fig. 16). Considering the past experience with testing the DSSATCROPGRO-Peanut response to temperature, we trust its temperature response more 


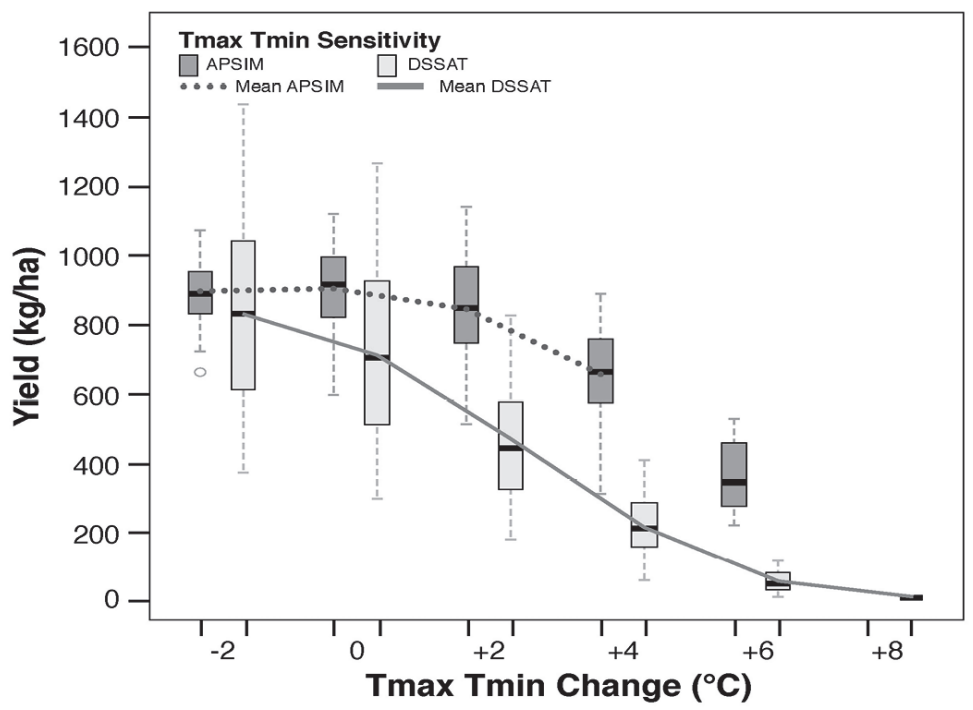

Fig. 16. Peanut seed yield simulated by APSIM-Peanut and DSSAT-CROPGRO-Peanut models, showing response to temperature at the Nioro site in Senegal.

than that of APSIM. In addition, since peanut is an $\mathrm{N}$-fixing legume, $\mathrm{N}$ limitation is not a constraint and is not reported here.

\section{Summary and Conclusions}

The CTWN exercise has helped us to appreciate and understand differences among APSIM and DSSAT crop models for their response to climatic and N fertilization factors. Similar analyses could also be performed to better understand differences between simulated cropping systems in the AgMIP Coordinated Climate-Crop Modeling Project (C3MP; McDermid et al., 2015) and the AgMIP Global Gridded Crop Model Intercomparison (GGCMI; Franke et al., 2020). The CTWN sensitivity analyses with the different models at different sites have been highly valuable for understanding the differential sensitivity of the APSIM and DSSAT models to climate change factors. It has provided several key insights.

The first insight is that the APSIM and DSSAT models mostly agree on their $\mathrm{CO}_{2}$ responsiveness for the different crops, both for C-4 and C-3 type crops. However, more importantly, responses to $\mathrm{CO}_{2}$ show interactions with $\mathrm{N}$ fertilization, being considerably muted in highly $\mathrm{N}$-deficient systems; thus, we are not seeing the benefit of rising $\mathrm{CO}_{2}$ that exists in well-fertilized fields (both models predict this). This means that climate change modeling for underdeveloped regions will benefit less from elevated $\mathrm{CO}_{2}$ than expected and that models (e.g., several global models) that 
do not account for degraded soils and low-N fertilization will give incorrect (too optimistic) responses to $\mathrm{CO}_{2}$.

The second insight is that the simulated sensitivity to rainfall is less than expected (for both models) because the simulated LAI for N-deficient crops is so low that transpiration demand and soil water depletion is small (except in the case of wellfertilized fields in the Republic of South Africa). In addition, simulations of rainfall response under low- $\mathrm{N}$ fertilization indicate that higher rainfall actually reduces yield because the small amount of available mineralized $\mathrm{N}$ is leached before the crop can capture it (both the APSIM and DSSAT models simulate this effect). Therefore, these two observations confirm strong interactions between rainfall variation and $\mathrm{N}$ fertilization.

This gives a second caution against climate change use of models (e.g., several global models) that cannot account for degraded soils and low-N fertilization because they will likely give incorrect (too much) response to rainfall variation. The highly $\mathrm{N}$-deficient systems may also affect the simulated response to $\mathrm{N}$ fertilization, where there may be positive effects of temperature where they are not expected, e.g., the soil $\mathrm{N}$ mineralization responds to rising temperature to provide more available $\mathrm{N}$, thus altering the temperature optimum for production (Kenya example). The APSIM and DSSAT models vary in this respect (soil $\mathrm{N}$ mineralization).

It is also of interest that the APSIM and DSSAT models frequently have similar responses to rainfall variation, despite different approaches for transpiration and soil water uptake. Where there are differences, DSSAT tends to predict stronger water limitations than APSIM.

The third insight or finding is that the APSIM and DSSAT models often differ in their temperature responses for different crops, which is not surprising considering they were separately developed and thus may have different temperature parameterizations for life cycle phenology, leaf area expansion, RUE/photosynthesis, grain set, and rate of grain filling. The DSSAT-CERES-Maize model is more sensitive than APSIM-Maize to elevated temperature, an outcome associated primarily with different parameterizations of rate of single-grain growth. There are also minor contributions caused by maize model differences in temperature parameterization of RUE and soil $\mathrm{C}$ mineralization. For three Kenyan sites differing in temperature (from elevation), the two models give different temperature response shapes with APSIM showing optimum yield at $+2^{\circ} \mathrm{C},+4^{\circ} \mathrm{C}$, and $+6^{\circ} \mathrm{C}$ depending on low-elevation to high-elevation sites.

The sorghum models in APSIM and DSSAT appear to have only minor differences in temperature response, with reasonable temperature response curves with optimum yield at $+2^{\circ} \mathrm{C}$. The millet models have minor differences in temperature response, and the APSIM-Millet showed almost no response $(+2$ to $+8^{\circ} \mathrm{C}$ ) which is not logical and needs further investigation. The CERES-Millet in DSSAT has moderate temperature sensitivity with an optimum response at 
$+2^{\circ} \mathrm{C}$. Both APSIM-wheat and DSSAT-CERES-Wheat show similar temperature responses, with declining yield with rising temperature for both Pakistan and northern India. The APSIM and DSSAT rice models similarly show reduced yield with rising temperature in Pakistan and northern India. For both wheat and rice crops and both models at these already warm sites, yield is improved with $-2{ }^{\circ} \mathrm{C}$ simulations.

While there are variations among the APSIM and DSSAT crop models on their temperature responses, we cannot give definitive statements as to which models are right because the necessary data on growth and yield at elevated temperatures for testing the models are often lacking. Even where such data are becoming available, the models have not been tested or modified from those data. The AgMIP-Wheat modelers have evaluated their models against the hot serial cereal experiment (Asseng et al., 2015) followed by improvements (Wang et al., 2017); however, the APSIM and CERES wheat models used in this study were versions fixed prior to any modifications based on those tests. Likewise, ongoing AgMIPRice modelers are evaluating rice models against elevated temperature experiments, but the present rice models have not benefitted from (or been modified by) those tests.

A fourth insight is that these exercises for low-input production on degraded soils have helped us to understand and guide model calibration for response to $\mathrm{N}$ fertilization relative to degraded soil conditions. The stable SOC fraction (DSSATCENTURY) or the fraction inert SOC (APSIM) must be adjusted to mimic the low yields obtained under zero $\mathrm{N}$ fertilization (depending on region because the present sites used only small amounts of $\mathrm{N}$ fertilizer). Knowledge of initial conditions of inorganic $\mathrm{N}$ in soil and prior crop residue is also important for predicting yield response to $\mathrm{N}$ fertilizer. Furthermore, the full response to $\mathrm{N}$ fertilization must be simulated $\left(0-210 \mathrm{~kg} \mathrm{Nha}^{-1}\right)$ in order to mimic the genetic potential of the cultivar. It is too easy (commonly done and too often), but absolutely incorrect, to modify genetic parameters of a cultivar to mimic the low yields under low-input production. Of course, the added problem is how to learn the genetic potential of the cultivar in question.

An additional caution for climate impact in low-input agriculture regions must be given relative to the effect of elevated temperature under climate change on SOC and $\mathrm{N}$ response when simulated with reinitiation of the models every year (as done in these exercises) as contrasted to continuous sequence/rotation stimulations. Basso et al. (2018) reported that $+3^{\circ} \mathrm{C}$ warming (climate change) will cause loss of SOC when simulated with carry-over sequence over the long term and the loss in SOC and $\mathrm{N}$ will cause an additional reduction in yields when compared to reinitiating the models every year. This means that global change models failing to account for soil $\mathrm{C}$ carry-over, soil degradation, and $\mathrm{N}$ mineralization over decades will be too optimistic for future climate change scenarios. 


\section{References}

Allen, R.G., Pereira, L.S. et al. 1998. Crop evapotranspiration. Guidelines for computing crop water requirements. FAO Irrigation and drainage paper no 56. FAO, Rome, Italy.

Asseng, S., Ewert, F. et al. 2015. Rising temperatures reduce global wheat production. Nat. Clim. Change, 5: 143-147.

Baker, J.T., Allen, L.H., Jr. et al. 1992a. Temperature effects on rice at elevated $\mathrm{CO}_{2}$ concentration. J. Exp. Bot., 252: 959-964.

Baker, J.T., Allen, L.H. Jr. et al. 1992b. Response of rice to $\mathrm{CO}_{2}$ and temperature. Agric. Forest Meterol., 60: 153-166.

Basso, B., Dumont, B. et al. 2018. Soil organic carbon and nitrogen feedbacks on crop yields under climate change. Agric. Environ. Lett., 3(180026). https://doi.org/10.2134/ael2018.05.0026

Basso, B., Gargiulo, O. et al. 2011. Procedures for initializing soil organic carbon pools in the DSSATCENTURY model for agricultural systems. Soil Sci. Soc. Am. J., 75: 69-78.

Basso, B., Liu, L. et al. 2016. A comprehensive review of the CERES-Wheat, -Maize and -Rice models' performances. Adv. Agron., 136: 27-132.

Bassu, S., Brisson, N. et al. 2014. How do various maize crop models vary in their responses to climate change factors. Global Change Biol., 20: 2301-2320, doi: 10.1111/gcb.12520.

Boote, K.J., Allen, L.H., Jr. et al. 2010. Testing effects of climate change in crop models. In: D. Hillel and C. Rosenzweig (eds.), Handbook of Climate Change and Agroecosystems. Imperial College Press, London UK.

Boote, K.J., Hoogenboom, G. et al. 2008. Modeling N-fixation and its relationship to N uptake in the CROPGRO model. In: L. Ma, L. Ahuja, and T. Bruulsema (eds.), Quantifying and Understanding Plant Nitrogen Uptake for Systems Modeling. Taylor \& Francis Group LLC, Boca Raton, Florida.

Boote, K.J. and Pickering, N.B. 1994. Modeling photosynthesis of row crop canopies. HortScience, 29: $1423-1434$.

Boote, K.J., Sau, F. et al. 2009. Experience with water balance, evapotranspiration, and prediction of water stress effects in the CROPGRO model. In: L.R. Ahuja, V.R. Reddy, S.A. Saseendran, and Q. Yu (eds.), Response of Crops to Limited Water: Modeling Water Stress Effects on Plant Growth Processes, Volume 1 of Advances in Agricultural Systems Modeling. ASA-CSSASSSA, Madison, Wisconsin.

Boote, K.J., Vara Prasad, L.H. et al. 2018. Modeling sensitivity of grain yield to elevated temperature in the DSSAT crop models for peanut, soybean, dry bean, chickpea, sorghum, and millet. Eur. J. Agron., 100: 99-109.

Bouman, B.A., Kropff, M.J. et al. 2001. Oryza2000: Modeling Lowland Rice. IRRI and Wageningen University, Los Banos, CA. ISBN is 971-22-0171-6.

Bouman, B.A.M. and van Laar, H.H. 2006. Description and evaluation of the rice growth model ORYZA2000 under nitrogen-limited conditions. Agric. Syst., 87: 249-273.

Carberry, P.S., Muchow, R.C. et al. 1989. Testing the CERES-Maize simulation model in a semi-arid tropical environment. Field Crops Res., 20: 297-315.

Falconnier, G.N., Corbeels, M. et al. 2019. Model intercomparison of maize response to climate change in low-input smallholder cropping systems. 3rd Agriculture and Climate Change Conference, Budapest, Hungary, 24-26 March 2019.

Franke, J., Müller, C. et al. 2020. The GGCMI Phase II experiment: Global gridded crop model simulations under uniform changes in $\mathrm{CO} 2$, temperature, water, and nitrogen levels (protocol version 1.0). Geosci. Model Dev., 13(5): 2315-2336, doi:10.5194/gmd-13-2315-2020.

Gaydon, D.S., Probert, M.E. et al. 2012. Rice in cropping systems - Modelling transitions between flooded and non-flooded soil environments. Eur. J. Agron., 39: 9-24. 
Gijsman, A.J., Hoogenboom, G. et al. 2002. Modifying DSSAT crop models for low-input agricultural systems using a soil organic matter-residue module from CENTURY. Agron. J., 94: 462-474.

Godwin, D.C. and Singh, U. 1998. Nitrogen balance and crop response to nitrogen in upland and lowland cropping systems. In: G.Y. Tsuji, G. Hoogenboom, and P.K. Thornton (eds.), Understanding Options for Agricultural Production, pp. 55-77. Kluwer Academic Publishers, Dordrecht, the Netherlands.

Hoogenboom, G., Jones, J.W. et al. 2015. Decision Support System for Agrotechnology Transfer (DSSAT) Version 4.5 (www.DSSAT.net). DSSAT Foundation, Prosser, Washington.

Holzworth, D.P., Huth, N.I. et al. 2014. APSIM — Evolution towards a new generation of agricultural systems simulation. Environmental Modelling and Software, 62: 327-350.

Jones, J.W., Hoogenboom, G. et al. 2003. The DSSAT cropping system model. Eur. J. Agron., 18(3-4): 235-265.

Keating, B.A., Carberry, P.S. et al. 2003. An overview of APSIM, a model designed for farming systems simulation. Eur. J. Agron., 18: 267-288.

Littleboy, M., Freebairn, D.M. et al. (1999). PERFECT Version 3.0 - A computer simulation model of Productivity Erosion Runoff Functions to Evaluate Conservation Techniques, 1-52.

Lizaso, J.I., Ruiz-Ramos, M. et al. 2017. Modeling the response of maize phenology, kernel set, and yield components to heat stress and heat shock with CSM-IXIM. Field Crops Res., 214: 239-252.

Lizaso, J.I., Ruiz-Ramos, M. et al. 2018. Impact of high temperatures in maize: Phenology and yield components. Field Crops Res., 216: 129-140.

McCown, R.L., Hammer, G.L. et al. 1996. APSIM: a novel software system for model development, model testing, and simulation in agricultural systems research. Agric. Syst., 50: 255-271.

McDermid, S.P., Ruane, A.C. et al. 2015. The AgMIP Coordinated Climate-Crop Modeling Project (C3MP): Methods and protocols. In Handbook of Climate Change and Agroecosystems: The Agricultural Model Intercomparison and Improvement Project (AgMIP) Integrated Crop and Economic Assessments, Part 1. C. Rosenzweig and D. Hillel, Eds., ICP Series on Climate Change Impacts, Adaptation, and Mitigation Vol. 3. pp. 191-220, Imperial College Press, London, UK. doi:10.1142/9781783265640_0008.

Naab, J.B., Singh, P. et al. 2004. Using the CROPGRO-peanut model to quantify yield gaps of peanut in the Guinean savanna zone of Ghana. Agron. J., 96: 1231-1242.

Nakagawa, H., Horie, T. et al. 1994. Environmental factors affecting rice responses to elevated carbon dioxide concentrations. Intl. Rice Res., Note 19: 45-46.

Penning de Vries, F.W.T., Brunsting, A.H.M. et al. 1974. Products requirements and efficiency of biosynthesis: A quantitative approach. J. Theor. Biol., 45: 339-377.

Pickering, N.B., Jones, J.W. et al. 1995. Adapting SOYGRO V5.42 for prediction under climate change conditions. In: C. Rosenzweig, J.W. Jones, and L.H. Allen, Jr. (eds.), Climate Change and Agriculture: Analysis of Potential International Impacts, pp. 77-98. ASA Spec. Pub. No. 59, ASA-CSSA-SSSA, Madison, Wisconsin.

Porter, C.H., Jones, J.W. et al. 2010. Modeling organic carbon and carbon-mediated soil processes in DSSAT v4.5. Oper. Res. Int. J., 10(3): 247-278. doi:10.1007/s12351-009-0059-1.

Prasad, P.V.V., Boote, K.J. et al. 2003. Supra-optimal temperatures are detrimental to peanut (Arachis hypogaea $\mathrm{L}$ ) reproductive processes and yield at ambient and elevated carbon dioxide. Glob. Change Biol., 9: 1775-1787.

Priestley, C.H.B. and Taylor, R.J. 1972. On the assessment of surface heat and evaporation using large scale parameters. Mon. Weather Rev., 100: 81-92.

Probert, M.E., Dimes, J.P. et al. 1998. APSIM's water and nitrogen modules and simulation of the dynamics of water and nitrogen in fallow systems. Agric. Syst., 56: 1-28. doi:10.1016/S0308521X(97)00028-0. 
Rattalino-Edreira, J.I., Budakli, C.E. et al. 2011. Heat stress effects around flowering on kernel set of temperate and tropical maize hybrids. Field Crop. Res., 123: 62-73.

Ritchie, J.T. 1985. A user-oriented model of the soil water balance in wheat. In: E. Fry and T.K. Atkin (eds.). Wheat Growth and Modeling, pp. 293-305. NATO-ASI Series. Plenum Press, New York.

Ritchie, J.T. 1998. Soil water balance and plant water stress. In: G.Y. Tsuji, G. Hoogenboom, and P.K. Thornton (eds.), Understanding Options for Agricultural Production, pp. 41-54. Kluwer Academic Publishers, Dordrecht, the Netherlands.

Rosenzweig, C., Jones, J.W. et al. 2013. The Agricultural Model Intercomparison and Improvement Project (AgMIP): Protocols and pilot studies. Agric. Forest Meteorol., 170: 166-182, doi:10.1016/j.agrformet.2012.09.011.

Rosenzweig, C., Antle, J.M. et al. 2017. Protocols for AgMIP Regional Integrated Assessments Version 7.0. Available at https://agmip.org/wp-content/uploads/2018/08/AgMIP-Protocols-for-Regi onal-Integrated-Assessment-v7-0-20180218-1-ilovepdf-compressed.pdf

Ruane, A.C., McDermid, S. et al. 2014. Carbon-temperature-water change analysis for peanut production under climate change: A prototype for the AgMIP Coordinated Climate-Crop Modeling Project (C3MP). Glob. Change Biol., 20(2): 394-407, doi:10.1111/gcb.12412.

Ruane, A.C., Rosenzweig, C. et al. 2017. An AgMIP framework for improved agricultural representation in IAMs. Environ. Res. Lett., 12(12): 125003, doi:10.1088/1748-9326/aa8da6.

Ruane, A.C., Goldberg, R., and Chryssanthacopoulos, J. 2015. AgMIP climate forcing datasets for agricultural modeling: Merged products for gap-filling and historical climate series estimation, Agr. Forest Meteorol., 200: 233-248, doi:10.1016/j.agrformet.2014.09.016.

Singh, P., Nedumaran, S. et al. 2014. Quantifying potential benefits of drought and heat tolerance in rainy season sorghum for adapting to climate change. Agr. \& Forest Met., 185: 37-48.

Thorburn, P., Boote, K. et al. 2015. Crop Systems Modeling in AgMIP: A new protocol-driven approach for regional integrated assessments. In: D. Hillel and C. Rosenzweig (eds.), Handbook of Climate Change and Agroecosystems: Agricultural Model Intercomparison and Improvement Project Integrated Crop and Economic Assessments (Vols. 3 \& 4). ICP Series on Climate Change Impacts, Adaptation, and Mitigation. Imperial College Press.

Van Uytrecht, E. and Thorburn, P.J. 2017. Responses to atmospheric $\mathrm{CO}_{2}$ concentrations in crop simulation models: A review of current simple and semicomplex representations and options for model development. Glob. Change Biol., 23: 1806-1820.

Wang, E.L., Martre P. et al. 2017. The uncertainty of crop yield projections is reduced by improved temperature response functions. Nat. Plants, 3: 1-13.

Ziska, L.H., Weerakoon, W. et al. 1996. The influence of nitrogen on the elevated $\mathrm{CO}_{2}$ response in field-grown rice. Aust. J. Plant Physiol., 23: 45-52. 